\title{
A CIRCULAÇÃo OCEÂNICA DE LARGA-ESCALA NA REGIÃO OESTE DO ATLÂNTICO SUL COM BASE NO MODELO DE CIRCULAÇÃO GLOBAL OCCAM
}

\author{
Mauro Cirano ${ }^{1}$, Mauricio M. Mata², Edmo J.D. Campos³ e Núbia F.R. Deiró4 \\ Recebido em 19 janeiro, 2006 / Aceito em 23 maio, 2006 \\ Received on January 19, 2006 / Accepted on May 23, 2006
}

\begin{abstract}
The OCCAM (Ocean Circulation and Climate Advanced Modeling Project) is one of the global ocean circulation models which has been commonly used by the Brazilian oceanographic community. In most cases it is associated to regional numerical modeling studies, where it provides initial and boundary conditions for higher resolution models. The aim of this work, based on the concept of water masses, is to compare on an annual basis, the OCCAM with the use of: i) climatological temperature and salinity data from the NODC (National Oceanographic Data Center) and ii) volume transports associated with the water masses and based on values available in the literature. The selected levels of comparison were chosen to represent the core of the main water masses of the South Atlantic and the associated currents, described based on their volume transports. The main results indicate that the model is capable of representing realistically the vertical structure of the main currents and the associated water masses for the study region. In the equatorial portion of the subtropical gyre the model shows, for example, the southward zonal migration of the South Equatorial Current bifurcation with the increase of depth. According to the model and for the Tropical Water level, the bifurcation occurs between $9^{\circ} \mathrm{S}-15^{\circ} \mathrm{S}$, moving to $25^{\circ} \mathrm{S}$ at the level of the South Atlantic Central Water and between $25^{\circ} \mathrm{S}-30^{\circ} \mathrm{S}$ at the level of the Antarctic Intermediate Water. The North Atlantic Deep Water, which is part of the thermohaline circulation, is represented in the model with a net southward transport between $15 \mathrm{~Sv}$ and $20 \mathrm{~Sv}$ for the region of study and is in agreement with the literature values.
\end{abstract}

Keywords: OCCAM, NODC, ocean circulation model, termohaline fields, South Atlantic, Tropical Water, South Atlantic Central Water, Antarctic Intermediate Water, North Atlantic Deep Water.

RESUMO. O OCCAM (Ocean Circulation and Climate Advanced Modelling Project) é um dos modelos de circulação global que vem sendo bastante utilizado pela comunidade oceanográfica brasileira, principalmente em estudos de modelagem numérica regional, onde fornece condições iniciais e de contorno para modelos numéricos mais detalhados da circulação. Este trabalho visa, através do conceito de massas de água, comparar no âmbito anual, os dados do OCCAM com: i) os dados climatológicos de temperatura e salinidade do NODC (National Oceanographic Data Center) e ii) os transportes de volume associados a estas massas de água, de acordo com os valores disponíveis na literatura. Os níveis de comparação foram escolhidos de forma a representar o núcleo das principais massas de água que compõe 0 Atlântico Sul e os sistemas de correntes que são descritos através dos transportes de volume associados às massas de água. Os principais resultados indicam que 0 modelo é capaz de representar realisticamente a estrutura vertical das principais correntes na região de estudo e as massas de água associadas. Na parte mais equatorial do giro subtropical o modelo apresenta, por exemplo, a migração zonal e para sul da bifurcação da Corrente Sul Equatorial com o aumento da profundidade. Segundo 0 OCCAM e para o nível da Água Tropical, esta bifurcação ocorre entre as latitudes de $9^{\circ} \mathrm{S}-15^{\circ} \mathrm{S}$, migrando para $25^{\circ} \mathrm{S}$ no nível da Água Central do Atlântico Sul e entre $25^{\circ} \mathrm{S}-30^{\circ} \mathrm{S}$ para o nível da Água Intermediária Antártica. A Água Profunda do Atlântico Norte, integrante da circulação termohalina, é representada pelo modelo com um transporte líquido para sul variando entre 15 Sv e 20 Sv ao longo da região de estudo e em concordância com o observado na literatura.

Palavras-chave: OCCAM, NODC, modelo de circulação global, campos termohalinos, Atlântico Sul, Água Tropical, Água Central do Atlântico Sul, Água Intermediária Antártica, Água Profunda do Atlântico Norte.

${ }^{1}$ Centro de Pesquisas em Geofísica e Geologia (CPGG), Universidade Federal da Bahia (UFBA), Instituto de Física, Departamento de Geofísica Nuclear, Campus Ondina, 40170-280 Salvador, BA, Brasil. Tel: (71) 3203-8612; Fax: (71) 3203-8501 - E-mail: mauro@cpgg.ufba.br

2Fundação Universidade Federal do Rio Grande (FURG), Departamento de Física, Rua Engenheiro Alfredo Huch, 475, 96201-900 Rio Grande, RS, Brasil. Tel: (53) 3233-6879; Fax: (53) 3233-6652 - E-mail: mauricio.mata@furg.br

3 Instituto Oceanográfico da Universidade de São Paulo (IOUSP), Departamento de Oceanografia Física, Praça do Oceanográfico, 191, Cidade Universitária, 05508-900 São Paulo, SP, Brasil. Tel: (11) 3091-6597; Fax: (11) 3091-6597 - E-mail: edmo@io.usp.br

${ }^{4}$ Centro de Pesquisas em Geofísica e Geologia (CPGG), Universidade Federal da Bahia (UFBA), Instituto de Geociências, Campus Ondina, 40170-280 Salvador, BA, Brasil. Tel: (71) 3203-8612; Fax: (71) 3203-8501 - E-mail: nfrd@cpgg.ufba.br 


\section{INTRODUÇÃo}

A circulação de larga-escala para a região oeste do Atlântico Sul vem sendo estudada principalmente: i) através de dados observacionais adquiridos em cruzeiros oceanográficos realizados durante as últimas décadas e ii) com base nos resultados provenientes de simulações numéricas da circulação oceânica, realizadas tanto no âmbito regional, como no âmbito global.

A utilização dos resultados gerados por simulações numéricas tem sido extremamente importante para a ampliação do conhecimento dos vários aspectos envolvidos na circulação oceânica. 0 sucesso da modelagem numérica está atrelado às seguintes razões: i) baixo custo operacional, uma vez que os computadores além de serem cada vez mais velozes, estão mais acessíveis e ii) possibilidade de estudar, de forma sinóptica, áreas geográficas bastante abrangentes e que provavelmente não poderiam ser cobertas no âmbito de um cruzeiro oceanográfico.

Com base nesta premissa, este trabalho tem como enfoque a análise, em escala de tempo anual, dos dados termohalinos e de velocidade provenientes do modelo de circulação global (resolução horizontal $1 / 4^{\circ} \times 1 / 4^{\circ}$ ) OCCAM (Ocean Circulation and Climate Advanced Modelling Project). Este estudo será realizado para região oeste do Atlântico Sul, compreendida pelos meridianos entre $20^{\circ} \mathrm{W}$ e $60^{\circ} \mathrm{W}$ e pelos paralelos entre 0 equador e $45^{\circ} \mathrm{S}$. Saunders et al. (1999), usando o mesmo modelo, realizaram um estudo similar para o 0ceano Pacífico como um todo. A comparação de modelos globais da circulação com resolução similar a proposta neste trabalho tem sido realizada no âmbito global por vários autores (e.g. Stammer et al., 1996; McClean et al., 1997), mas não foi encontrado na literatura nenhum estudo voltado especificamente para a região proposta.

Atualmente, a maioria dos estudos oceanográficos no Atlântico Sul, é voltada aos aspectos gerais da circulação, aos padrões principais dos campos de temperatura e salinidade e às características das massas de água. Peterson \& Stramma (1991), considerando a coluna d'água como um todo, e Stramma \& England (1999) e Silveira et al. (2000), considerando um oceano dividido em várias camadas, apresentam compilações dos vários trabalhos que descrevem os principais sistemas de correntes e as massas de água associadas para este oceano.

Partindo-se das camadas superficiais até o nível da termoclina, a corrente mais importante que flui ao longo da costa brasileira é a Corrente do Brasil (CB), que é a corrente de contorno oeste associada ao Giro Subtropical do Atlântico Sul (Figura 1). A CB se origina da bifurcação do ramo sul da Corrente Sul Equatorial (CSE), ao sul de $10^{\circ} \mathrm{S}$, e flui para sul, bordejando o continente sul-americano até a região da Convergência Subtropical, localizada entre $38^{\circ} \mathrm{S} \pm 2^{\circ}$ (Olson et al., 1988), onde forma a confluência com a Corrente das Malvinas e se afasta da costa. A CSE, também dá origem à Corrente Norte do Brasil (CNB) (Stramma, 1991; Silveira et al., 1994), que por sua vez, flui em direção ao equador. A CB, quando comparada as outras correntes de contorno oeste, é uma corrente rasa, e em muitas ocasiões apresenta seu eixo de corrente acima da isóbata de $200 \mathrm{~m}$ (Tomczak \& Godfrey, 1994).

A extensão vertical da CB, de acordo com o argumento teórico utilizado é variável, como apresentado por Silveira et al. (2000). Neste artigo, será utilizada a definição da CB como o fluxo associado ao movimento de duas massas de água (Água Tropical - AT e Água Central do Atlântico Sul - ACAS). Esta definição, utilizada por vários autores, baseia-se no conceito teórico de que a $\mathrm{CB}$, como uma corrente de contorno oeste, requer um transporte de Sverdrup para completar o balanço de massa gerado pelo vento no Giro Subtropical.

A AT, como uma água superficial, é formada devido à intensa radiação e ao excesso de evaporação em relação à precipitação, característicos do Atlântico Sul equatorial, sendo transportada para Sul pela CB. Emilson (1961) caracterizou a AT por águas com temperaturas maiores do que $20^{\circ} \mathrm{C}$ e salinidades acima de 36 ups.

A ACAS, segundo Miranda (1985), é caracterizada por temperaturas superiores a $6^{\circ} \mathrm{C}$ e inferiores a $20^{\circ} \mathrm{C}$ e por salinidades entre 34,6 e 36 ups. Sua formação acontece na zona de confluência da CB com a Corrente das Malvinas e isto, segundo Stramma \& England (1999), é o fator responsável por sua alta salinidade. Silveira et al. (2000) descrevem a ACAS como uma massa de água pertencente ao Giro Subtropical, que circula com as Correntes do Atlântico Sul e de Benguela, e atinge a costa da América do Sul transportada pela CSE. Existe um consenso na literatura de que ao sul do Cabo de São Tomé $\left(22^{\circ}\right.$ S) uma parte da ACAS flui para Sul ao longo da Costa Brasileira e outra parte flui rumo ao equador (Wüst, 1935; Defant, 1941; Tsuchya, 1986; Reid, 1989; Stramma \& England, 1999).

A massa de água localizada imediatamente abaixo da ACAS é a Água Intermediária Antártica (AIA), definida por Sverdrup et al. (1942), pelos limites termohalinos de $3^{\circ}-6^{\circ} \mathrm{C}$ para temperatura e 34,2-34,6 ups para salinidade. Enquanto apresenta-se como uma corrente de contorno oeste bem definida, a AIA movese na direção do equador ao norte de $25^{\circ} \mathrm{S}$, fluindo para 0 sul em $28^{\circ} \mathrm{S}$ (Müller et al., 1998). Stramma \& England (1999) centram 0 eixo da bifurcação da AIA ao sul de $25^{\circ} \mathrm{S}$. Esta bifurcação ocorreria próximo à latitude de Santos, mas com 0 eixo da divergência ocorrendo praticamente paralelo ao talude. 


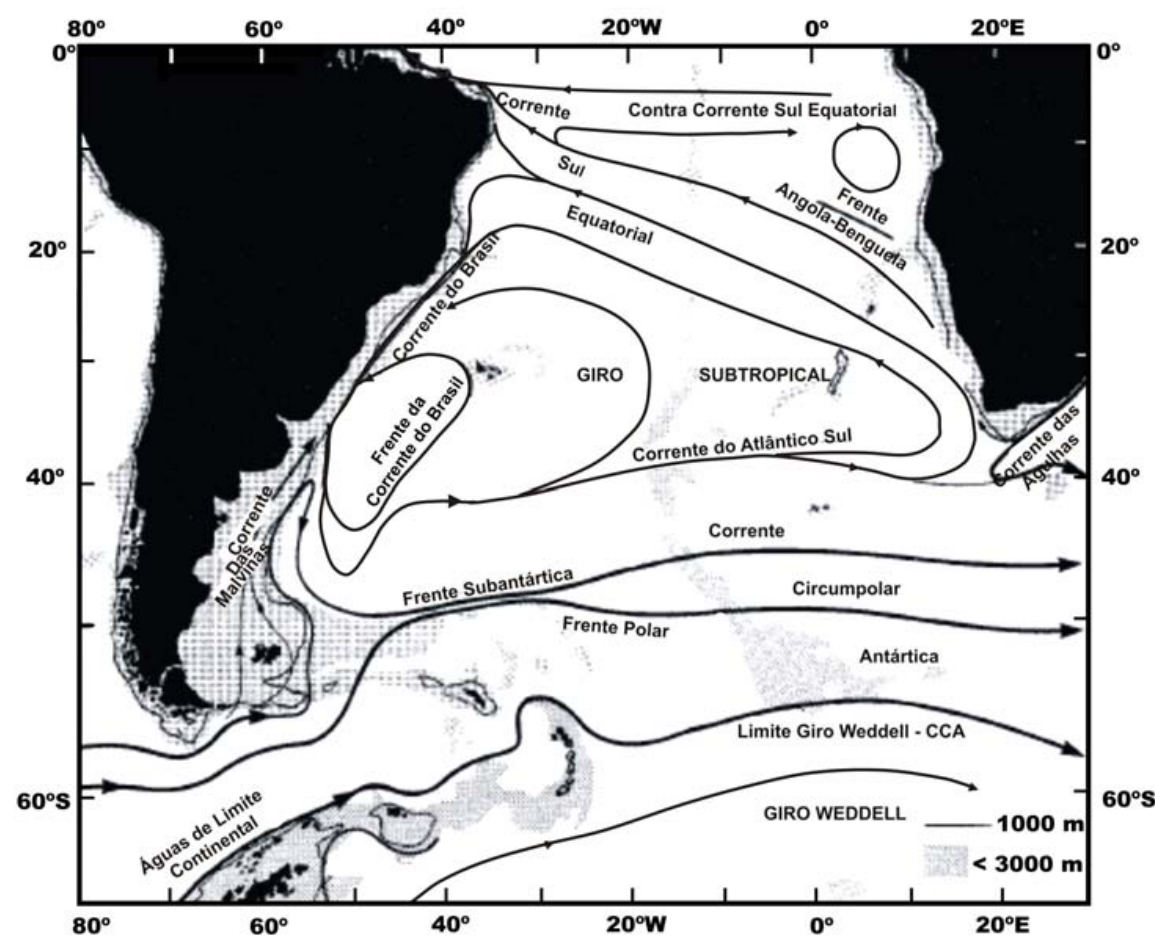

Figura 1 - Representação esquemática do Giro Subtropical do Atlântico Sul. Modificado de Peterson \& Stramma (1991)

A Água Profunda do Atlântico Norte (APAN), situada logo abaixo da AIA e parte integrante da circulação termohalina, é caracterizada por valores de temperatura entre $3^{\circ}-4^{\circ} \mathrm{C}$ e salinidades entre 34,6-35,0 ups, ocupando níveis entre $1500 \mathrm{~m}$ e $3000 \mathrm{~m}$ ao largo do Sudeste brasileiro (Silveira et al., 2000). Apresenta-se como um fluxo organizado, fluindo para o sul ao longo do contorno oeste até cerca de $32^{\circ} \mathrm{S}$, onde pelo menos parte da corrente retorna em direção ao equador (Reid, 1989; Weatherly, 1993).

Tendo como base os aspectos gerais da circulação oceânica e das massas de água associadas descritas acima, este trabalho tem como objetivos:

- Realizar uma análise crítica do erro associado aos campos termohalinos e de corrente do OCCAM, para diversas profundidades ao longo da coluna d'água. Tal análise será importante para a utilização destes dados climatológicos como condições iniciais (no caso da temperatura e a salinidade) e de contorno (como a velocidade integrada ao longo da coluna d'água) em modelos regionais da circulação. Tal procedimento vem sendo adotado com sucesso em várias regiões do globo (e.g. Mellor \& Ezer, 1991; Oey \& Chen, 1992; Cirano \& Middleton, 2004)
- Descrever os padrões mais importantes de circulação associados às principais massas de água e sistemas de correntes que compõe o Atlântico Sul.

\section{METODOLOGIA}

\section{O Modelo OCCAM e o processo de comparação}

0 OCCAM é um modelo numérico global da circulação oceânica que utiliza as equações primitivas formuladas em coordenadas ze desenvolvidas por Bryan, Cox e Semtner (Bryan, 1969; Semtner, 1974; Cox, 1984). Vide Tabela 1 para configuração do modelo numérico, sendo que uma descrição mais detalhada pode ser obtida em Webb et al. (1998).

A comparação dos dados do OCCAM foi realizada de duas formas distintas. Para os dados termohalinos, foi utilizada como comparação a climatologia proveniente do World Ocean Atlas do National Oceanographic Data Center (NODC), descrito em Boyer et al. (2005). Os dados provenientes da climatologia do NODC representam uma compilação de todos os dados termohalinos obtidos em cruzeiros oceanográficos ao longo de todo 0 globo até o presente, sendo assim uma excelente ferramenta para comparação. Coincidentemente, a malha de interpolação adotada 
Tabela 1 - Principais características do modelo numérico de circulação oceânica OCCAM.

\begin{tabular}{|c|c|}
\hline Parâmetros do Modelo & Valores \\
\hline Resolução Horizontal & Grade Arakawa B, com 1/4 de grau em latitude e Iongitude \\
\hline Resolução Vertical & $\begin{array}{l}36 \text { camadas, com espessura variando entre } 20 \text { m (próximo à } \\
\text { superfície) e } 255 \text { m (profundidade de } 5500 \text { m). As } 8 \text { camadas } \\
\text { iniciais encontram-se nos primeiros } 200 \text { m da coluna d'água }\end{array}$ \\
\hline Intervalo de integração & 18 s (barotrópico) e 900 s (baroclínico) \\
\hline Condições de contorno & Velocidade igual à zero em todos os limites sólidos \\
\hline Batimetria & Dados da US Navy DBDB5 com resolução de 1/12 de grau \\
\hline Coeficiente de difusão & $100 \mathrm{~m}^{2} / \mathrm{s}$ (horizontal) e $1 \mathrm{~cm}^{2} / \mathrm{s}$ (vertical) \\
\hline Coeficiente de viscosidade & $200 \mathrm{~m}^{2} / \mathrm{s}$ (horizontal) e $1 \mathrm{~cm}^{2} / \mathrm{s}$ (vertical) \\
\hline Forçantes: tensão do vento & Climatologia mensal do ECMWF (Siefridt \& Barnier, 1993) \\
\hline $\begin{array}{c}\text { Forçantes: fluxos de calor } \\
\text { e água doce }\end{array}$ & $\begin{array}{l}\text { Escala de } 30 \text { dias de "relaxamento" para a climatologia mensal } \\
\text { do Levitus (Levitus \& Boyer, 1994; Levitus et al., 1994) }\end{array}$ \\
\hline Funcionamento do modelo & $\begin{array}{l}\text { Simula a circulação por um período de } 14 \text { anos. } 0 \text { período } \\
\text { recomendado para a análise encontra-se entre os dias } 2922 \\
\text { e 4383, referentes aos anos } 8 \text { até } 12 \text { do modelo } \\
\text { (Webb et al., 1998) }\end{array}$ \\
\hline
\end{tabular}

pelo NODC é idêntica à utilizada pelo OCCAM, não sendo necessário nenhuma interpolação horizontal dos dados. A única interpolação adotada foi a da coordenada vertical, para que os dados do NODC, que se encontram disponibilizados de acordo com as profundidades padrão, pudessem ser comparados com os níveis verticais do modelo OCCAM. Os dados de temperatura do NODC também foram convertidos para temperatura potencial, que é a medida de temperatura adotada pelo OCCAM. 0 erro foi calculado da seguinte forma:

$$
\text { Erro }=\text { Modelado }(\text { OCCAM })-\text { Observado (NODC) }
$$

Para o campo de velocidade, e devido à ausência de um atlas climatológico para as correntes, decidiu-se pela utilização do transporte de volume, como instrumento de comparação. Silveira et al. (2000) apresentam uma tabela descrevendo estes trabalhos relacionados à CB, a qual foi atualizada e encontra-se reproduzida na Tabela 2. Para a avaliação do transporte de volume, a área de estudo foi dividida em várias sub-regiões, escolhidas de forma a ilustrar as variações mais significativas de transporte entre duas regiões vizinhas. Um procedimento similar foi adotado por Middleton \& Cirano (2002).

A análise do transporte de volume tem como objetivo investigar a circulação das principais correntes e massas de água associadas para a região de estudo, verificando até que ponto 0 modelo OCCAM é capaz de representar a circulação de larga escala para a região. Para realizar tal comparação, considerou-se que as massas de água ocupam camadas de água relativamente definidas ao longo da coluna d'água. Para a definição das caixas horizontais, foram então analisados vários perfis de velocidade (tanto zonais como meridionais) ao longo da área de estudo, com 0 intuito de escolher as sub-regiões mais significativas para a avaliação dos transportes de volume. Para a escolha dos níveis verticais, foram levados em consideração: i) as profundidades de inversão das correntes diagnosticadas nestes perfis avaliados, ii) os níveis das massas de água obtidos nestas comparações e iii) as definições adotadas no trabalho de Stramma \& England (1999). Com isto, foram definidas as seguintes faixas de profundidade: (i) AT - entre as profundidades de 0 a $116 \mathrm{~m}$, ii) ACAS entre as profundidades de $116 \mathrm{~m}$ e $657 \mathrm{~m}$, iii) AIA - entre $657 \mathrm{~m}$ e $1234 \mathrm{~m}$ e iv) APAN - entre $1234 \mathrm{~m}$ e $3472 \mathrm{~m}$. A escolha de faixas isopicnais, ao invés da adoção de profundidades fixas, seria provavelmente mais realística, uma vez que uma mesma massa de água pode ocupar níveis distintos ao longo da costa brasileira. No entanto, como o OCCAM é um modelo que utiliza coordenadas z, a adoção de níveis isopicnais, envolveria uma série de interpolações horizontais e verticais para o cálculo dos transportes associados, o que poderia comprometer o balanço de volume dentro das caixas. A Figura 2 apresenta uma distribuição das massas de água ao longo da coluna d'água para 4 latitudes distintas dentro da região de estudo. Os dados referentes às massas de água situadas em profundidades abaixo de $3500 \mathrm{~m}$ só aparecem na comparação dos valores integrados ao longo da coluna d'água. 
Tabela 2 - Estimativas para 0 transporte de volume e velocidade máxima da $\mathrm{CB}$, entre $9^{\circ} \mathrm{S}$ e $31^{\circ} \mathrm{S}$. Extraída de Silveira et al. (2000) e atualizada.

\begin{tabular}{|c|c|c|c|l|}
\hline $\begin{array}{c}\text { Latitude } \\
(\mathrm{S})\end{array}$ & $\begin{array}{c}\text { Profundidade } \\
\text { de Referência } \\
(\mathrm{m})\end{array}$ & $\begin{array}{c}\text { Transporte } \\
\text { de volume } \\
\left(10^{6} \mathrm{~m}^{3} \mathrm{~s}^{-1}\right)\end{array}$ & $\begin{array}{c}\text { Velocidade } \\
\text { Máxima } \\
\left(\mathrm{m} \mathrm{s}^{-1}\right)\end{array}$ & \multicolumn{1}{|c|}{$\begin{array}{c}\text { Referência } \\
\text { Bibliográfica }\end{array}$} \\
\hline $9^{\circ}-13^{\circ}$ & $390-510$ & 4,1 & 0,31 & Stramma et al. (1990) \\
$15^{\circ}$ & $470-530$ & 6,0 & 0,16 & Stramma et al. (1990) \\
$19^{\circ}$ & 500 & 6,5 & 0,72 & Miranda \& Castro (1981) \\
$19^{\circ}$ & 500 & 5,3 & 0,50 & Evans et al. (1983) \\
$19^{\circ} 25^{\prime}$ & $470-640$ & 5,7 & 0,19 & Stramma et al. (1990) \\
$20^{\circ} 03^{\prime}$ & $590-630$ & 1,6 & 0,24 & Stramma et al. (1990) \\
$20^{\circ} 28^{\prime}$ & $500 / 1000$ & $3,8 / 6,8$ & 0,52 & Evans et al. (1983) \\
$21^{\circ} 40^{\prime}$ & 500 & 4,4 & 0,61 & Evans et al. (1983) \\
$22^{\circ}$ & $500-1300$ & 5,2 & 0,19 & Signorini (1978) \\
$23^{\circ}$ & $500-1300$ & 4,4 & 0,52 & Signorini (1978) \\
$23^{\circ}$ & 550 & $2,2 / 2,7$ & 0,49 & Miranda \& Castro (1979) \\
$23^{\circ}$ & Pegasus & 11 & 0,50 & Evans \& Signorini (1985) \\
$23^{\circ}$ & Pegasus & 6 & 0,70 & Garfield (1990) \\
$23^{\circ}$ & Pegasus & $5,4 \pm 1,4$ & 0,50 & Silveira et al. (2004) \\
$23^{\circ}$ & $600 / 1300$ & $10,1 / 10,9$ & - & Stramma (1989) \\
$23^{\circ} 30^{\prime}$ & $500-1300$ & 8,0 & 0,75 & Signorini (1978) \\
$24^{\circ}$ & 1300 & 7,5 & 0,25 & Fisher (1964) \\
$24^{\circ}$ & $500-1300$ & 14,0 & 0,62 & Signorini (1978) \\
$24^{\circ}$ & $500 / 1000$ & $4,1 / 7,8$ & 0,31 & Evans et al. (1983) \\
$24^{\circ}$ & $600 / 1300$ & $9,4 / 10,1$ & - & Stramma (1989) \\
$24^{\circ}$ & Correntômetro & 1,3 & - & Müller et al. (1998) \\
$24^{\circ} 30^{\prime}$ & $500-1300$ & 13,2 & 0,68 & Signorini (1978) \\
$25^{\circ}$ & 750 & 7,3 & 0,60 & Campos et al. (1995) \\
$28^{\circ}$ & Correntômetro & 16 & - & Müller et al. (1998) \\
$28^{\circ}-30^{\circ}$ & $1550-1600$ & 11,4 & 0,70 & Fisher (1964) \\
$31^{\circ}$ & Pegasus & 18 & 0,80 & Garfield (1990) \\
\hline
\end{tabular}

A utilização de caixas para a avaliação do transporte, considerando-se a situação onde a coluna d'água foi analisada como um todo, permitiu estimativas de balanço de transporte para cada caixa com um erro da ordem de 0,05 Sv.

Para a comparação da temperatura e da salinidade, foi adotada a camada do OCCAM mais próxima do núcleo de cada uma das massas de água em questão. De acordo com esta premissa, as camadas selecionadas foram: i) camada 3 (profundidade de $52 \mathrm{~m}$ ) representando a AT, ii) camada 10 (profundidade de $295 \mathrm{~m}$ ) representando a ACAS, iii) camada 17 (profundidade de $989 \mathrm{~m}$ ), representando a AIA e iv) camada 22 (profundidade $1931 \mathrm{~m}$ ) representando a APAN.

\section{RESULTADOS}

Uma importante simplificação que pode ser aplicada para 0 entendimento da dinâmica dos oceanos é a aquela onde 0 oceano é reduzido a uma situação bi-dimensional e 0 fluxo ao longo da coluna d'água é considerado como um fluxo único. Vários aspectos da circulação oceânica podem ser interpretados a partir desta aproximação.

Desta forma, antes de apresentarmos detalhadamente a estrutura das massas de água, tanto associada ao transporte de volume como aos parâmetros termohalinos, será realizada uma análise dos resultados obtidos com base no transporte de volume inte- 


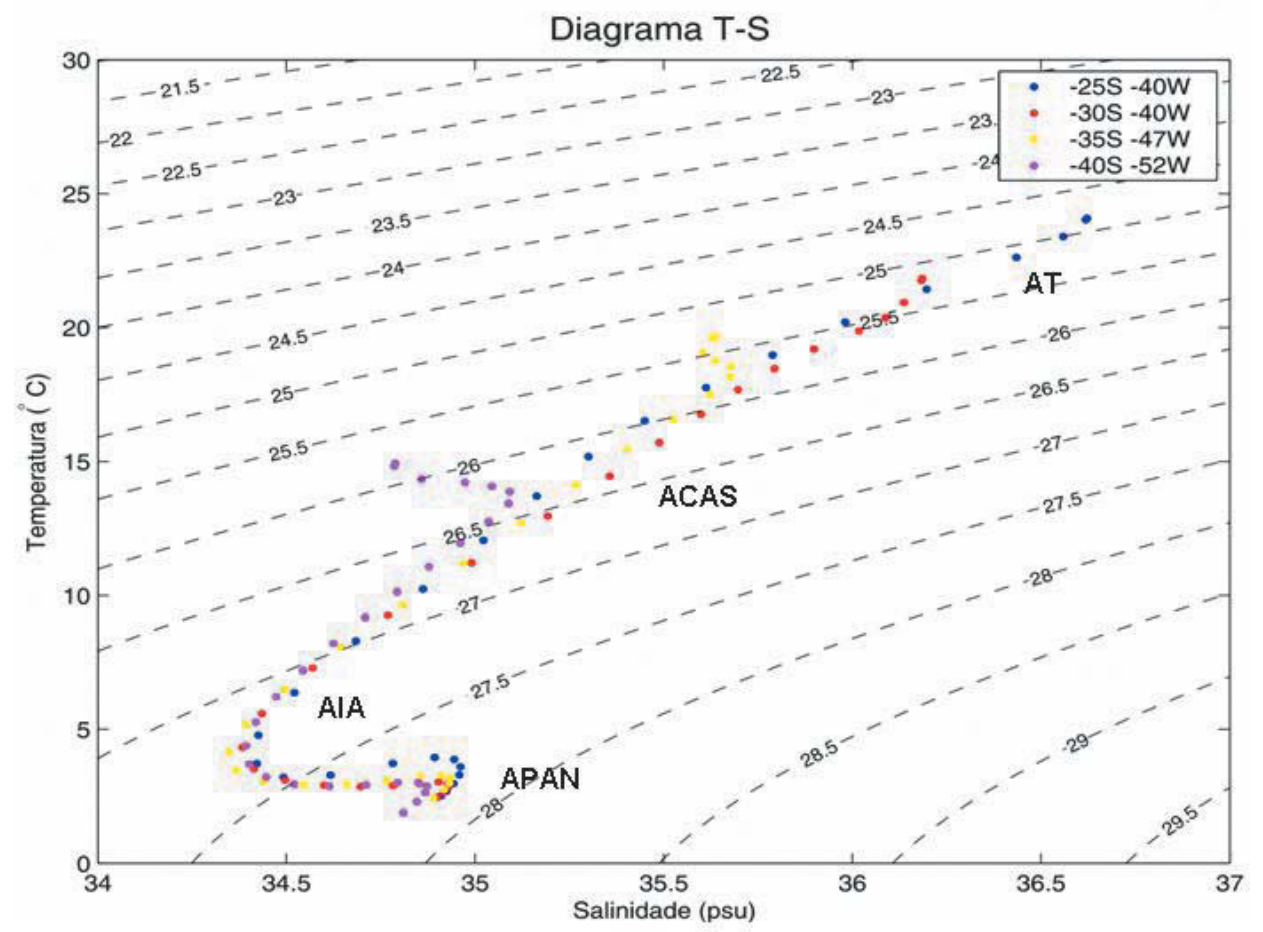

Figura 2 - Diagrama TS espalhado mostrando a distribuição das massas de água segundo o OCCAM e para 4 pontos distintos de latitude ao longo da costa brasileira.

grado ao longo da coluna d'água. Godfrey (1989) usando a climatologia anual de ventos de Hellerman \& Rosenstein (1983) e com base no modelo de Sverdrup, obteve transportes variando entre $0 \mathrm{~Sv}\left(10^{\circ} \mathrm{S}\right)$ até um máximo de $35 \mathrm{~Sv}\left(30^{\circ} \mathrm{S}\right)$, representado pela parte mais interior do giro subtropical. Os resultados baseados na climatologia do OCCAM (Figura 3) mostram uma boa similaridade com o proposto por Godfrey (1989), onde 0 transporte líquido máximo associado ao giro subtropical também atingiu um valor de aproximadamente $35 \mathrm{~Sv}$. Pela Figura 3, também é possível observar uma outra similaridade importante, que está na posição latitudinal das linhas de transporte zero e máximo, que ocorreram em latitudes próximas das observadas por Godfrey (1989). No entanto, os resultados do OCCAM apresentam uma distribuição zonal do transporte mais variável do que a proposta pelo autor acima, onde o incremento de transporte ao longo do giro varia quase que linearmente entre as latitudes de $10^{\circ} \mathrm{S} \mathrm{e}$ $30^{\circ} \mathrm{S}$.

Com relação às massas de água, e analisando a coluna d'água com base em 4 camadas distintas, podemos observar que para 0 nível associado com a AT, representado pelas profundidades en- tre $0 \mathrm{~m}$ e $116 \mathrm{~m}$, a distribuição horizontal das propriedades termohalinas a $52 \mathrm{~m}$ (Figura 4) mostra a AT fluindo desde as regiões tropicais, onde é formada, até a latitude de $35^{\circ} \mathrm{S}$, onde aparece como uma língua de água mais quente e salina ao longo do talude continental. Este limite máximo de penetração é marcado pela isoterma de $20^{\circ} \mathrm{C}$ e pela isohalina de 36 ups, segundo a definição de Emilson (1961). Os máximos valores de temperatura ocorrem entre $10^{\circ} \mathrm{S}-15^{\circ} \mathrm{S}$ e não ultrapassam os $26^{\circ} \mathrm{C}$ (Figura 4a), enquanto os máximos valores de salinidade, atingindo 37 ups, ocorrem um pouco mais ao sul, ao longo da costa sul da Bahia (Figura 4b).

A análise dos erros associados à temperatura (Figura 4c) e salinidade (Figura 4d) mostra que a região mais suscetível a erros éa da convergência subtropical. A estatística apresentada na Tabela 3 (média \pm desvio padrão) mostra um valor de $-0,71 \pm 1,38^{\circ} \mathrm{C}$ para a temperatura $\mathrm{e}-0,19 \pm 0,18$ ups para a salinidade. É interessante observar que existe uma considerável compensação dos erros de temperatura e salinidade, o que felizmente resulta em uma diminuiçã̃o do erro da densidade, que apresentou um valor de $0,03 \pm 0,21$ para $\sigma_{\theta}$. Desta forma, as águas relativamente mais frias segundo o OCCAM, são compensadas por valores mais 


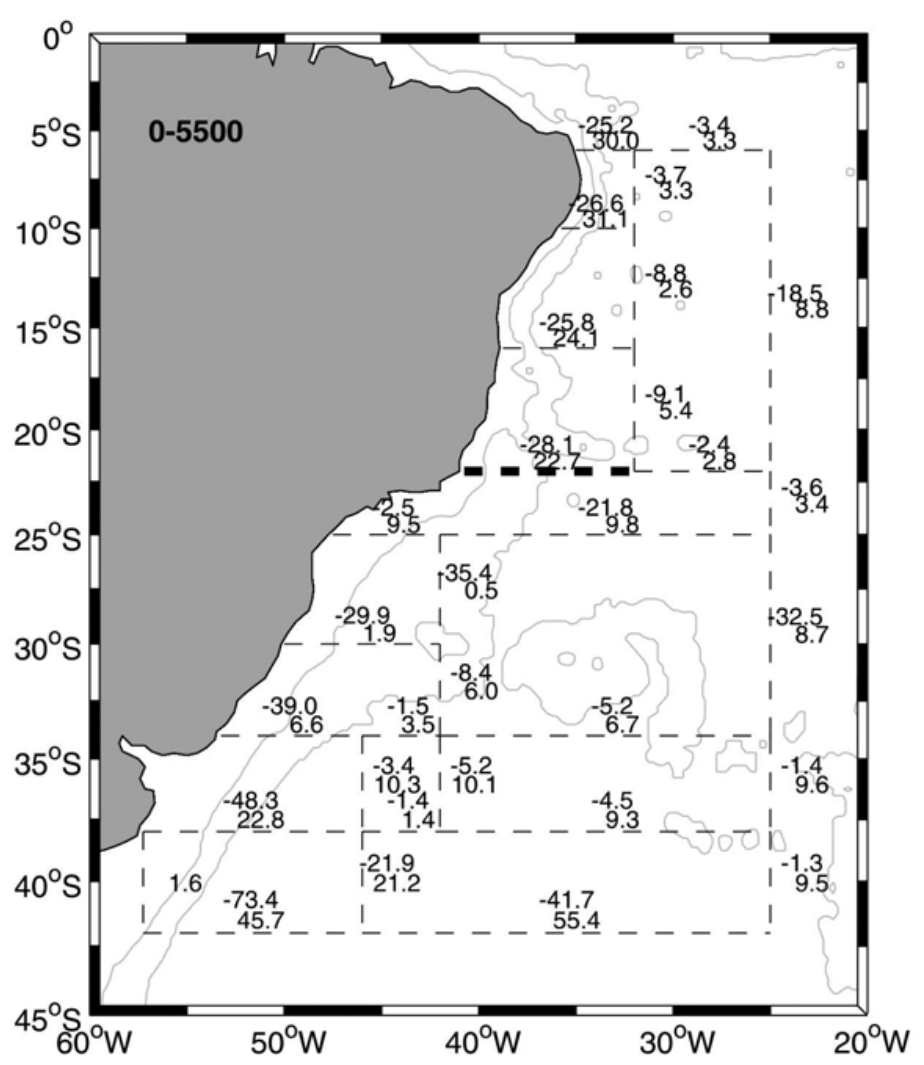

Figura 3 - Mapa das caixas contendo os transportes de volume (em Sv, onde $1 \mathrm{~Sv}=10^{6} \mathrm{~m}^{3} \mathrm{~s}^{-1}$ ) ao longo da área de estudo e com base na coluna de água como um todo (profundidade de $0-5500 \mathrm{~m}$ ). Os valores positivos (negativos) representam fluxos para norte (sul) ou leste (oeste). Quando um dos valores for inferior a $0,5 \mathrm{~Sv}$, será indicado apenas o transporte líquido. Um exemplo pode ser evidenciado através da linha em destaque que mostra um transporte de 22,5 Sv para norte e um transporte de 28,1 Sv para sul, resultando em um transporte líquido de 5,4 Sv para sul.

baixos de salinidade. Tais discrepâncias estão provavelmente associadas a erros nos fluxos de calor e água doce que alimentam o modelo. Uma possível causa para este erro pode estar relacionada, como será mostrado na Figura 14, a uma subestimativa da profundidade da camada de mistura, principalmente para as regiões ao norte de $30^{\circ} \mathrm{S}$, onde os valores são menores e no caso da temperatura existe uma ampla região com erros próximos a $1^{\circ} \mathrm{C}$. Para a região entre $35^{\circ} \mathrm{S}-40^{\circ} \mathrm{S}$, onde os valores são mais elevados, os erros devem estar associados à posição latitudinal da frente-subtropical (principalmente no caso da temperatura) e ao posicionamento meridional da confluência Brasil-Malvinas, onde principalmente na salinidade, existe um erro na forma de um dipolo.

A Figura 5, que apresenta os transportes de volume para a lamina d'água compreendida entre a superfície e a profundidade de
116 m mostra, em analogia com o diagrama esquemático apresentado por Stramma \& Schott (1999), o ramo sul da CSE penetrando zonalmente pela região entre $9^{\circ} \mathrm{S}-22^{\circ} \mathrm{S}$, com um transporte líquido associado de 3,0 Sv. A CSE, ao atingir a região do talude continental e da quebra da plataforma, dá origem a CNB, que flui para norte e pode ser observada, de uma forma mais organizada, em latitudes inferiores a $10^{\circ} \mathrm{S}$, com um transporte líquido associado de até 2,5 Sv. Fluindo para sul, e em latitudes superiores a $15^{\circ} \mathrm{S}$ observa-se a $\mathrm{CB}$, que tem seu transporte intensificado a medida que fui rumo ao sul, até atingir um máximo de 5,1 Sv em latitudes superiores a $35^{\circ} \mathrm{S}$. No entanto, o máximo transporte líquido para sul (3,7 Sv) ocorre ao longo de $30^{\circ} \mathrm{S}$. Um aspecto interessante que pode ser observado na região costeira limitada pelas latitudes entre $10^{\circ} \mathrm{S}$ e $25^{\circ} \mathrm{S}$ é 0 aporte de transporte causado pela ressurgência de águas de camadas mais profundas. 0 

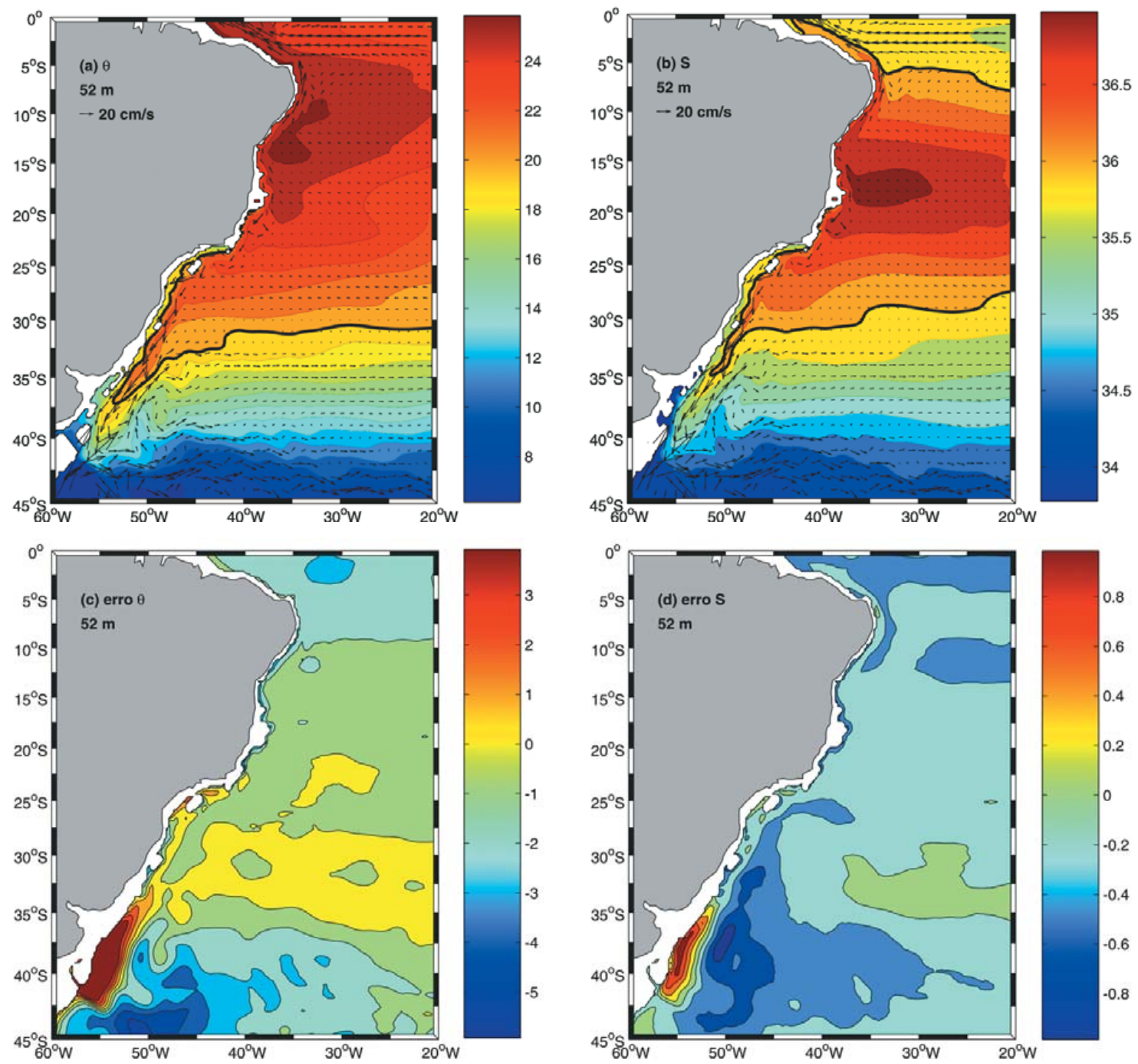

Figura 4 - Distribuição horizontal da (a) temperatura potencial (espaçamento de $1,0^{\circ} \mathrm{C}$ entre as isotermas) e da (b) salinidade (espaçamento de 0,25 ups entre as isohalinas) segundo a climatologia anual do OCCAM e para a profundidade de $52 \mathrm{~m}$. Os vetores de velocidade (1 em cada 4), assim como um destaque da isoterma de $20^{\circ} \mathrm{C}$ em (a) e da isohalina de 36 ups em (b) também foram incluídos nas figuras (a) e (b). (c) Distribuição horizontal do erro para a temperatura potencial (espaçamento de $1,0^{\circ} \mathrm{C}$ entre as linhas), obtido pela diferença entre 0 apresentado em (a) e a climatologia anual do NODC, interpolado para a mesma profundidade e convertido em temperatura potencial. (d) Análogo a (c), mas para a salinidade (espaçamento de 0,25 ups entre as linhas).

transporte total resultante da soma destas três caixas costeiras é de 2,0 Sv e provavelmente está associado a componente NE do vento, promovendo a subida das águas de camadas mais profundas para profundidades mais rasas, mas sem a necessidade da mesma atingir a superfície do oceano. Ainda com relação à região costeira, a seção localizada a $15^{\circ} \mathrm{S}$ e em analogia com 0 observado por Stramma et al. (1990), evidencia a presença de um jato costeiro oposto a CB e com intensidade de 1,4 Sv.
Para 0 nível associado com a ACAS (profundidades entre $116 \mathrm{~m}$ e $657 \mathrm{~m}$ ), a distribuiçã̃o horizontal das propriedades termohalinas a $295 \mathrm{~m}$, mostra de forma bastante clara que a ACAS flui em dois sentidos distintos ao longo da costa brasileira. Para esta profundidade o máximo valor de temperatura é de $16^{\circ} \mathrm{C}$ (Figura 6a). A isoterma de $15^{\circ} \mathrm{C}$ pode ser usada, por exemplo, como um traçador para avaliar a região de penetração e bifurcação da ACAS ao longo da costa brasileira. 0 mapa de temperatura 
Tabela 3 - Erro médio e desvio padrão da temperatura potencial, salinidade e para as profundidades de: $52 \mathrm{~m}$ (AT), $295 \mathrm{~m}$ (ACAS), $989 \mathrm{~m}$ (AIA) e $1931 \mathrm{~m}$ (APAN). 0 erro é definido como o valor obtido segundo a climatologia do OCCAM subtraído do valor obtido segundo a climatologia do NODC.

\begin{tabular}{|c|c|c|c|}
\hline \multicolumn{5}{|c|}{ Erro Médio } \\
\hline Profundidade (m) & Salinidade (ups) & Temperatura $\left({ }^{\circ} \mathrm{C}\right)$ & $\sigma_{\theta}$ \\
\hline 52 (AT) & $-0,19$ & $-0,71$ & 0,03 \\
295 (ACAS) & 0,00 & 0,81 & $-0,15$ \\
989 (AIA) & 0,04 & 0,39 & $-0,01$ \\
1931 (APAN) & $-0,01$ & 0,06 & $-0,01$ \\
\hline \hline \multicolumn{4}{|c|}{ Desvio Padrão } \\
\hline Profundidade (m) & Salinidade (ups) & Temperatura $\left({ }^{\circ} \mathrm{C}\right)$ & $\sigma_{\theta}$ \\
\hline 52 (AT) & 0,18 & 1,38 & 0,21 \\
295 (ACAS) & 0,17 & 1,17 & 0,12 \\
989 (AIA) & 0,05 & 0,33 & 0,03 \\
1931 (APAN) & 0,02 & 0,13 & 0,01 \\
\hline
\end{tabular}

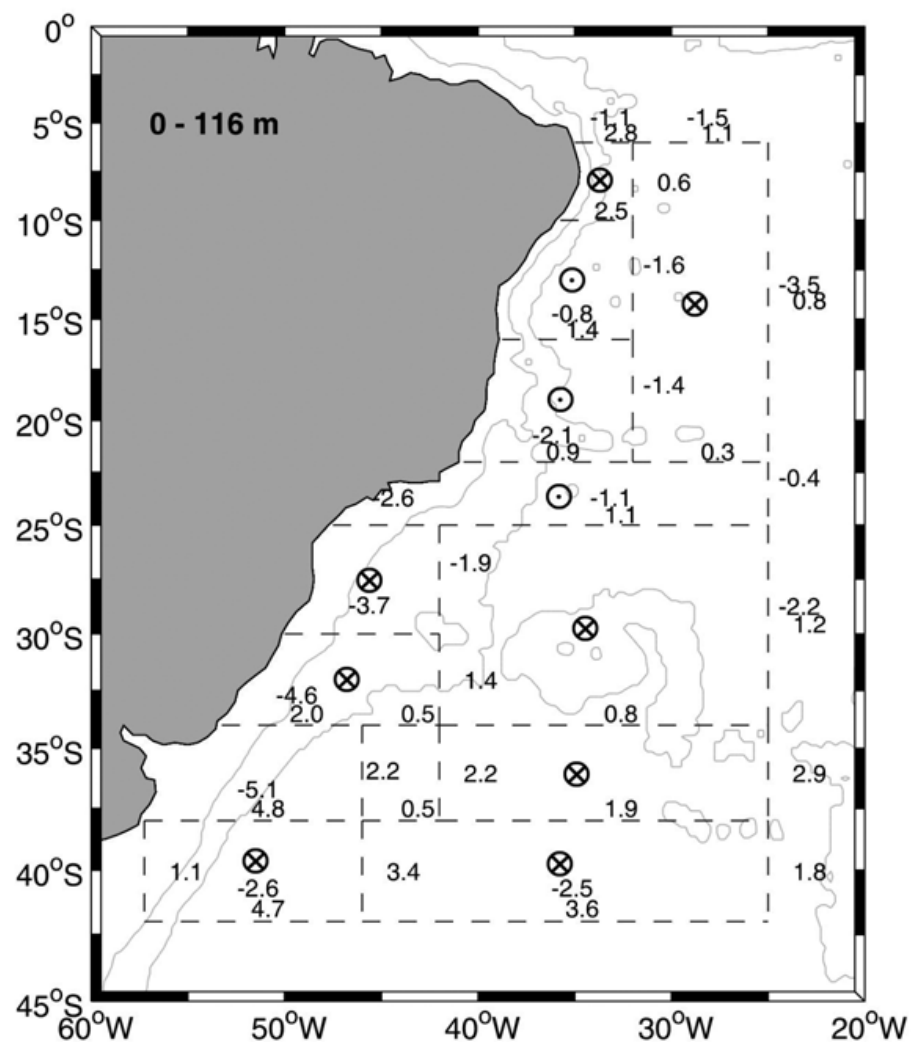

Figura 5 - Mapa das caixas contendo os transportes de volume (em Sv) ao longo da área de estudo e para as profundidades entre $0-116 \mathrm{~m}$, equivalente à AT. Os símbolos no centro das caixas indicam ressurgência $(\bullet)$ e subsidência $(\otimes)$ e só são indicados onde o transporte associado é superior a 0,2 Sv. Os valores positivos (negativos) representam fluxos para norte (sul) ou leste (oeste). No caso de um dos valores ser inferior a 0,5 Sv, é indicado apenas o transporte líquido. 

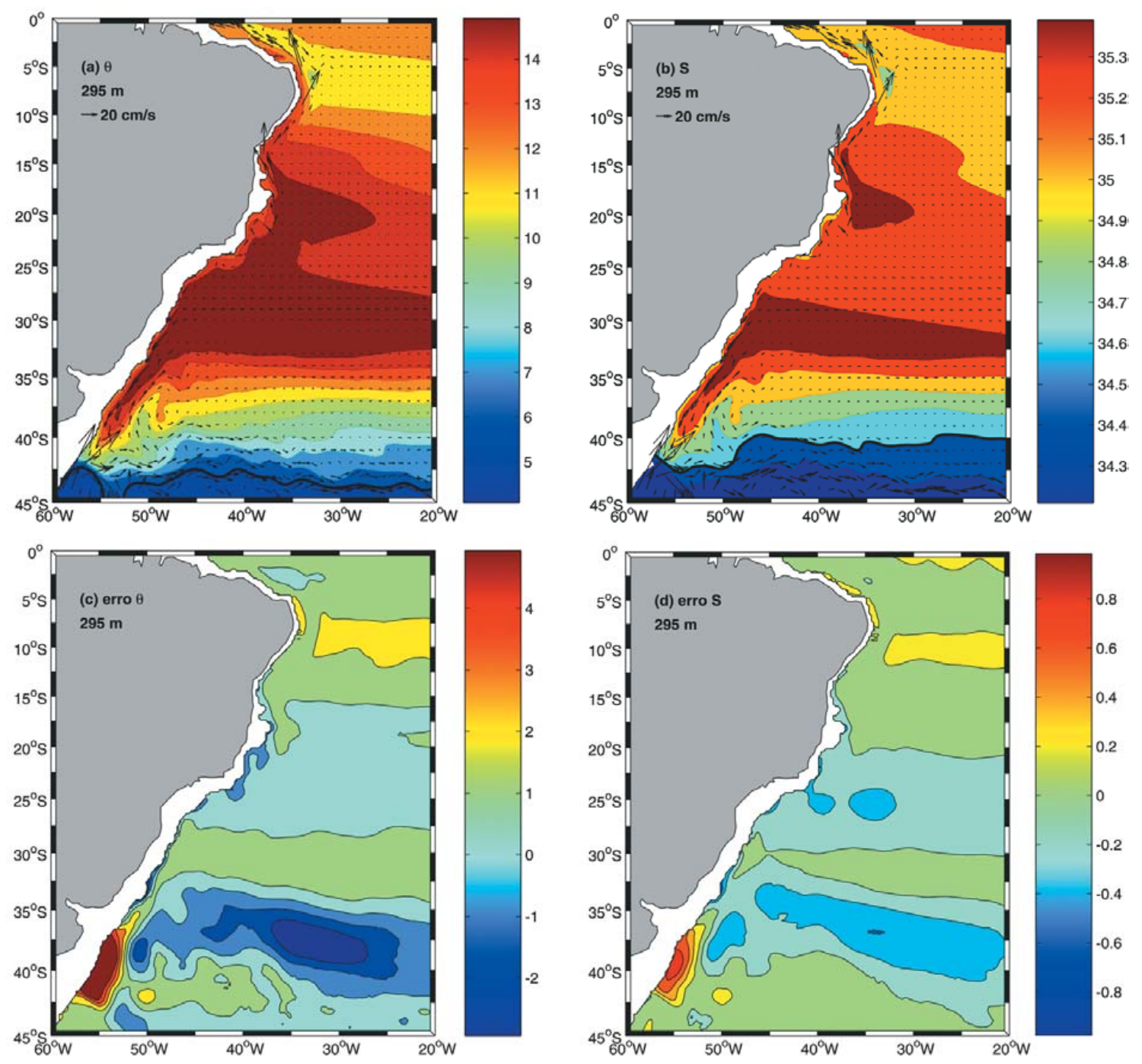

Figura 6 - Análoga a Figura 4, porém para a profundidade de $295 \mathrm{~m}$. As isolinhas em destaque são (a) a isoterma de $6^{\circ} \mathrm{C}$ e (b) isohalina de 34,6 ups. 0 espaçamento entre as isohalinas em (b) é de 0,2.

mostra que para latitudes inferiores a $25^{\circ} \mathrm{S}$ existe um nítido fluxo da ACAS em direção Norte, principalmente considerando-se que este é o núcleo desta massa de água. 0 fluxo para sul pode ser observado até a latitude de $42^{\circ} \mathrm{S}$ e é marcado pela isoterma de $6^{\circ} \mathrm{C}$. A Figura $6 \mathrm{~b}$ apresenta a distribuição de salinidade e mostra dois núcleos máximos em torno de 35,4 ups, um entre $15^{\circ} \mathrm{S}-$ $20^{\circ} \mathrm{S}$ e outro entre $30^{\circ} \mathrm{S}-35^{\circ} \mathrm{S}$. 0 limite sul de ocorrência da ACAS, marcado pela isohalina de 34,6 ups é semelhante ao limite térmico mencionado acima.

Para a profundidade de $295 \mathrm{~m}$, o mapa dos erros associados à temperatura (Figura 6c) e salinidade (Figura 6d) mostra nova- mente a convergência subtropical como a região mais suscetível a erros. É interessante observar, entretanto, que a estatística dos erros apresentada na Tabela 3 (média \pm desvio padrão) é distinta do nível da AT. Para a ACAS, os erros associados à temperatura e a salinidade são de respectivamente $0,81 \pm 1,17^{\circ} \mathrm{C}$ e $0,00 \pm 0,17$ e mostram que as águas do OCCAM são relativamente mais quentes, resultando em um erro médio de densidade de $-0,15 \pm 0,12$ para $\sigma_{\theta}$. Apesar do erro médio associado com a densidade ser pelo menos 5 vezes maior do que 0 encontrado para os outros níveis analisados, é importante lembrar que este nível localiza-se na região da termoclina, onde os gradien- 


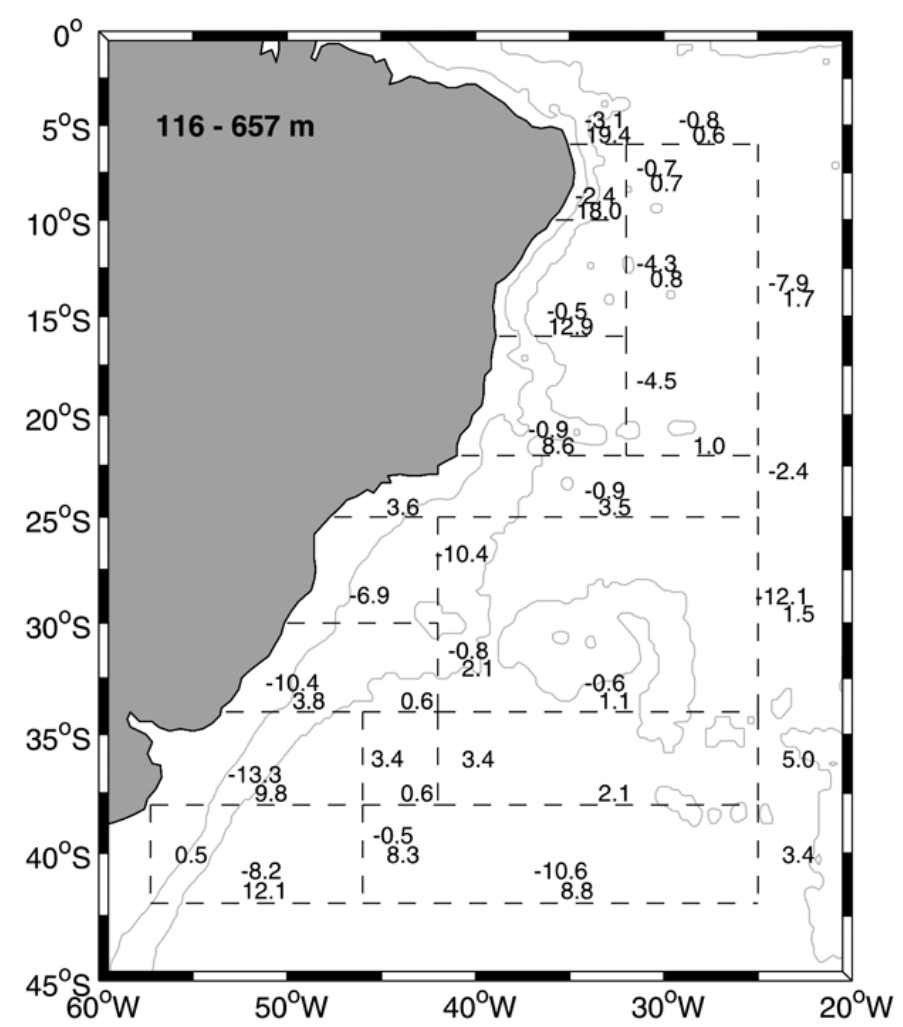

Figura 7 - Análoga a Figura 5, mas para as profundidades entre $116 \mathrm{~m}-657 \mathrm{~m}$, equivalente a ACAS.

tes térmicos são muito intensos. Se este valor fosse convertido para profundidade, este erro estaria certamente associado a poucas dezenas de metros.

A Figura 7 mostra a ACAS penetrando zonalmente (entre a faixa de $6^{\circ} \mathrm{S}-34^{\circ} \mathrm{S}$ ) totalizando um transporte líquido em direção à costa brasileira de 19,2 Sv. Uma parte substancial deste transporte penetra ao sul de $25^{\circ} \mathrm{S}$ e está associado à própria retroalimentação do giro subtropical. 0 transporte líquido da ACAS rumo ao sul na seção mais próxima à costaé de no máximo 6,9 Sv, na latitude de $30^{\circ} \mathrm{S}$. Em latitudes equatoriais, o máximo transporte líquido (neste caso fluindo para norte) é de pelo menos 0 dobro deste valor, atingindo um máximo de 16,3 Sv. Este é 0 fluxo associado com a Subcorrente Norte do Brasil (SNB). Silveira et al. (1994), estimaram os transportes geostróficos para seções normais à costa entre $5^{\circ} \mathrm{S}$ e $10^{\circ} \mathrm{S}$ e entre as profundidades de $0 \mathrm{~m}$ e 500-550 m e encontraram valores variando entre 15 e $22 \mathrm{~Sv}$. A análise das 2 seções normais a costa localizadas na parte mais equatorial do domínio, apresentou transportes líquidos (nível da AT e ACAS) para norte de 18 Sv e muito similares aos observados pelos autores acima. Mémery et al. (2000) Iocalizaram o início da
SNB para o nível da ACAS em $23^{\circ} \mathrm{S}$. A distribuição de transportes do OCCAM mostra que existe entre $22^{\circ} \mathrm{S}-25^{\circ} \mathrm{S}$ uma grande variação do transporte para norte neste nível, sendo a latitude de $25^{\circ} \mathrm{S}$ o início da SNB. Isto pode ser evidenciando de uma forma mais clara no mapa de temperatura apresentado na Figura 6a.

Para o nível da AIA (profundidades entre $657 \mathrm{~m}$ e $1234 \mathrm{~m}$ ), os mapas com a distribuiçã̃o horizontal das propriedades termohalinas a $989 \mathrm{~m}$ evidenciam novamente 0 deslocamento zonal para sul da região de bifurcação da AIA, que aparece centrada próximo de $30^{\circ} \mathrm{S}$. Os núcleos de máxima temperatura, evidenciados pela isoterma de $4,2^{\circ} \mathrm{C}$ (Figura 8a) e de mínima salinidade, evidenciados pelo isohalina de 34,35 ups (Figura 8b) podem ser utilizados como indicadores da propagação da AIA em direção à costa brasileira. 0 limite sul da AIA, marcado pela isoterma de $3^{\circ} \mathrm{C}$ oscila entre as latitudes de $42^{\circ} \mathrm{S}-43^{\circ} \mathrm{S}$, onde a AIA pode ser observada fluindo para leste pela Corrente do Atlântico Sul, como parte integrante do contorno sul do giro subtropical.

0 mapa dos erros associados à distribuição de temperatura (Figura 8c) e salinidade (Figura 8d) para a profundidade de $989 \mathrm{~m}$ em conjunção com a Tabela 3 , mostra erros de $0,39 \pm 0,33^{\circ} \mathrm{C}$ 

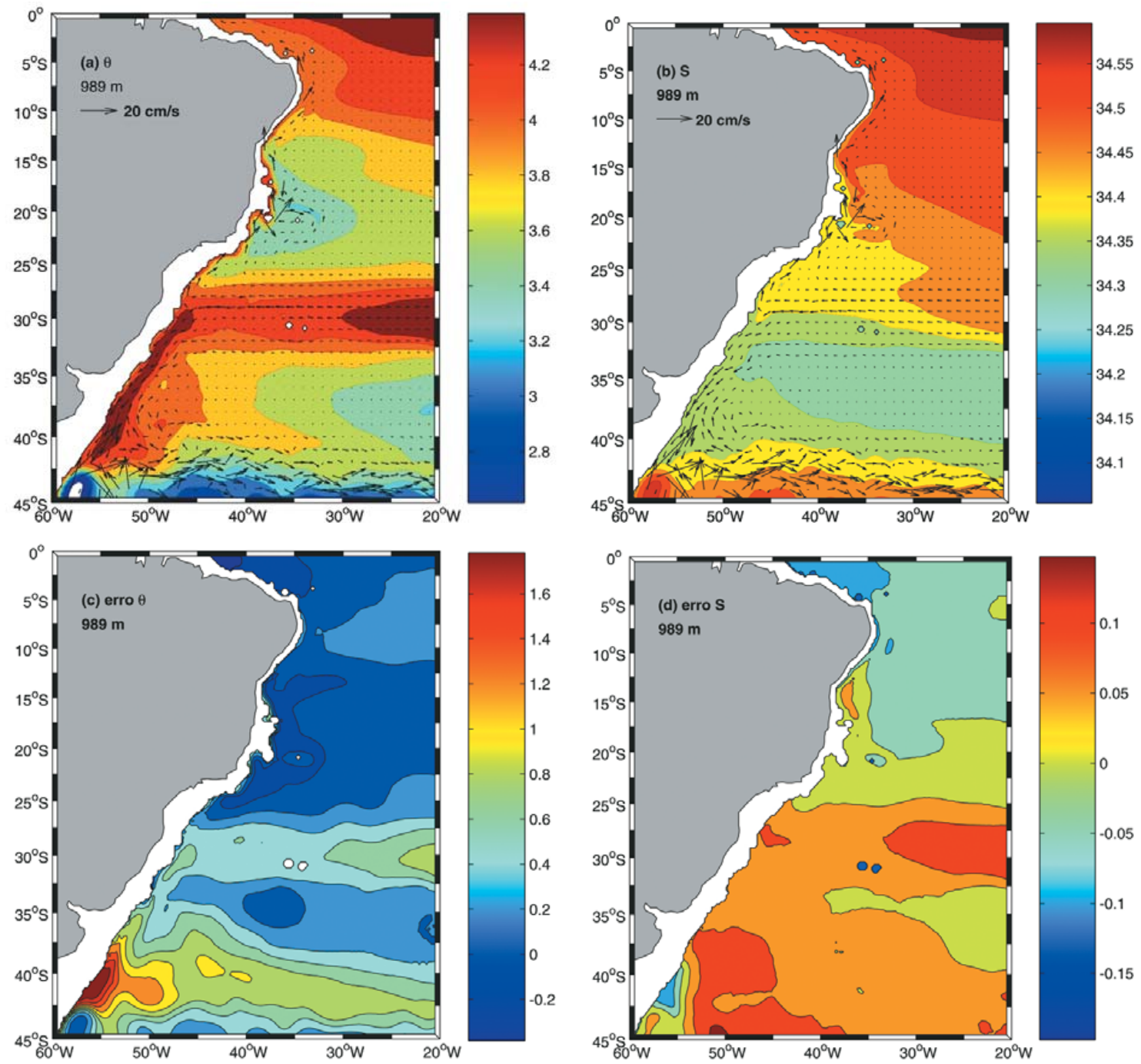

Figura 8 - Análoga a Figura 4, mas para a profundidade de $989 \mathrm{~m}$. (a) e (c) espaçamento de 0,2 para as isotermas. (b) e (d) espaçamento de 0,05 para as isohalinas.

e $0,04 \pm 0,05$ ups para temperatura e salinidade respectivamente. A combinação dos erros de temperatura e salinidade é quase totalmente compensada na densidade, resultando em um erro de apenas $-0,01 \pm 0,03$ para $\sigma_{\theta}$.

Em termos de transporte, a Figura 9 mostra a AIA penetrando zonalmente pela região de estudo entre as latitudes de $25^{\circ} \mathrm{S}-$ $34^{\circ} \mathrm{S}$ e com um transporte associado de 9,8 Sv. Boebel et al. (1999), através da compilação de dados de flutuadores definem um padrão semelhante para a penetração zonal da AIA, a qual está associada a um transporte de 12, $0 \pm 3,0 \mathrm{~Sv}$. Nuñez-Riboni et al. (2005), e também com base em flutuadores, estimam um transporte para oeste, relativo à parte norte do giro subtropical de
$9,3 \pm 3,4 \mathrm{~Sv}$, entre $22^{\circ} \mathrm{S}-32^{\circ} \mathrm{S}$. Segundo o OCCAM, a zona de bifurcação da AIA próxima à costa ocorre entre $25^{\circ} \mathrm{S}-30^{\circ} \mathrm{S}$ e concorda com os estudos de correntometria realizados por Müller et al. (1998), onde a AIA, na forma de uma Corrente de Contorno Oeste Intermediária, fluiria para 0 equador, ao norte de $25^{\circ} \mathrm{S}$ e para sul em $28^{\circ} \mathrm{S}$. Segundo o OCCAM, a AIA apresentou um transporte líquido para norte variando entre um mínimo de 2,9 Sv (próximo do equador) e um máximo de 6,2 Sv (próximo à cadeia Vitória-Trindade). Schmid (1998) usando seções do WOCE estimou transportes de $7,7 \mathrm{~Sv}\left(19^{\circ} \mathrm{S}\right), 4,0 \mathrm{~Sv}\left(21^{\circ} \mathrm{S}\right)$ e 2,7 Sv $\left(24^{\circ} \mathrm{S}\right)$. Silveira et al. (2004), entre $22^{\circ} \mathrm{S}$ e $23^{\circ} \mathrm{S}$, calcularam com base em medidas diretas, um transporte de $3,6 \pm 0,8 \mathrm{~Sv}$. Na direção 


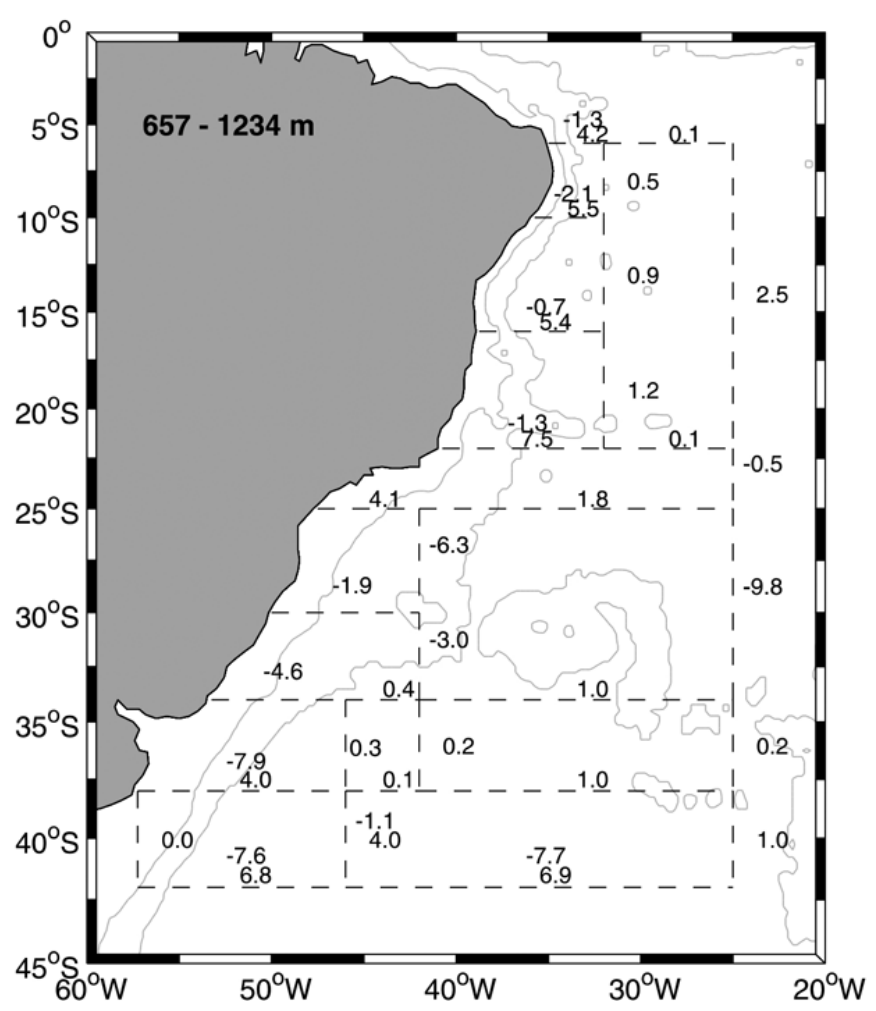

Figura 9 - Análoga a Figura 5, mas para as profundidades entre 657 m-1234 m, equivalente a AIA.

oposta, o máximo transporte líquido da AIA, segundo o OCCAM foi de 4,6 Sv (34 $)$ ). Schmid (1998) define uma relação de 1:2 para a divisão do fluxo norte e sul da AIA, sendo o último o mais intenso. Os resultados do OCCAM, no entanto, não apresentam um padrão semelhante e indicam uma proporção similar entre os 2 fluxos. Na parte sul da região de estudo, e em analogia com Reid et al. (1977), a AIA flui para leste na confluência Brasil-Malvinas ( $~ 38^{\circ} \mathrm{S}$ ), apresentando um padrão bastante meandrante (vide os relativamente altos transportes fluindo tanto para sul como para norte), formando parte de uma recirculação mais profunda associada ao Giro Subtropical.

Para o nível da APAN, representada entre profundidades de 1234 m e 3472 m, observa-se pela distribuição horizontal das propriedades termohalinas $(1931 \mathrm{~m})$ que existe um completo domínio desta massa de água ao longo da região de estudo para as latitudes ao norte de $25^{\circ} \mathrm{S}$. Para a faixa de latitude entre $25^{\circ} \mathrm{S}$ e $38^{\circ} \mathrm{S}$ a penetração sul da APAN fica restrita a região do talude continental. Os máximos valores de temperatura ocorrem na forma de um núcleo entre $20^{\circ} \mathrm{S}-30^{\circ} \mathrm{S}$, atingindo valores de $3,7^{\circ} \mathrm{C}$ (Figura 10a). A salinidade, por sua vez, apresenta um decréscimo contínuo a medida que se propaga rumo ao pólo sul, apresentando um língua de máxima salinidade próximo a 34,98 ups com máxima penetração austral associada à latitude de $15^{\circ} \mathrm{S}$ (Figura 10b). A distribuição da temperatura mostra que a APAN retorna para o giro subtropical somente ao sul de $40^{\circ} \mathrm{S}$, como será evidenciado pelos transportes de volume.

0 erro associado à temperatura e a salinidade para esta profundidade já é bastante reduzido, porém continua concentrado próximo à região da confluência. A análise da Tabela 3 e dos mapas de erros (Figuras 10c e 10d) mostra que o modelo está superaquecendo $\left(0,06 \pm 0,13^{\circ} \mathrm{C}\right)$ e subestimando a salinidade $(-0,01 \pm 0,02$ ups), sendo que estes dois parâmetros contribuem para um erro médio para a densidade de $-0,01 \pm 0,01$ para $\sigma_{\theta}$.

Em termos de transporte de volume, a APAN (Figura 11) aparece com um fluxo muito organizado em direção sul, cruzando toda a costa brasileira com seu núcleo sempre atrelado à região do talude continental, e apresentando transportes líquidos variando entre 15 e 20 Sv. A seção mais ao sul do domínio evidencia o padrão meandrante deste fluxo, quando a APAN é observada 

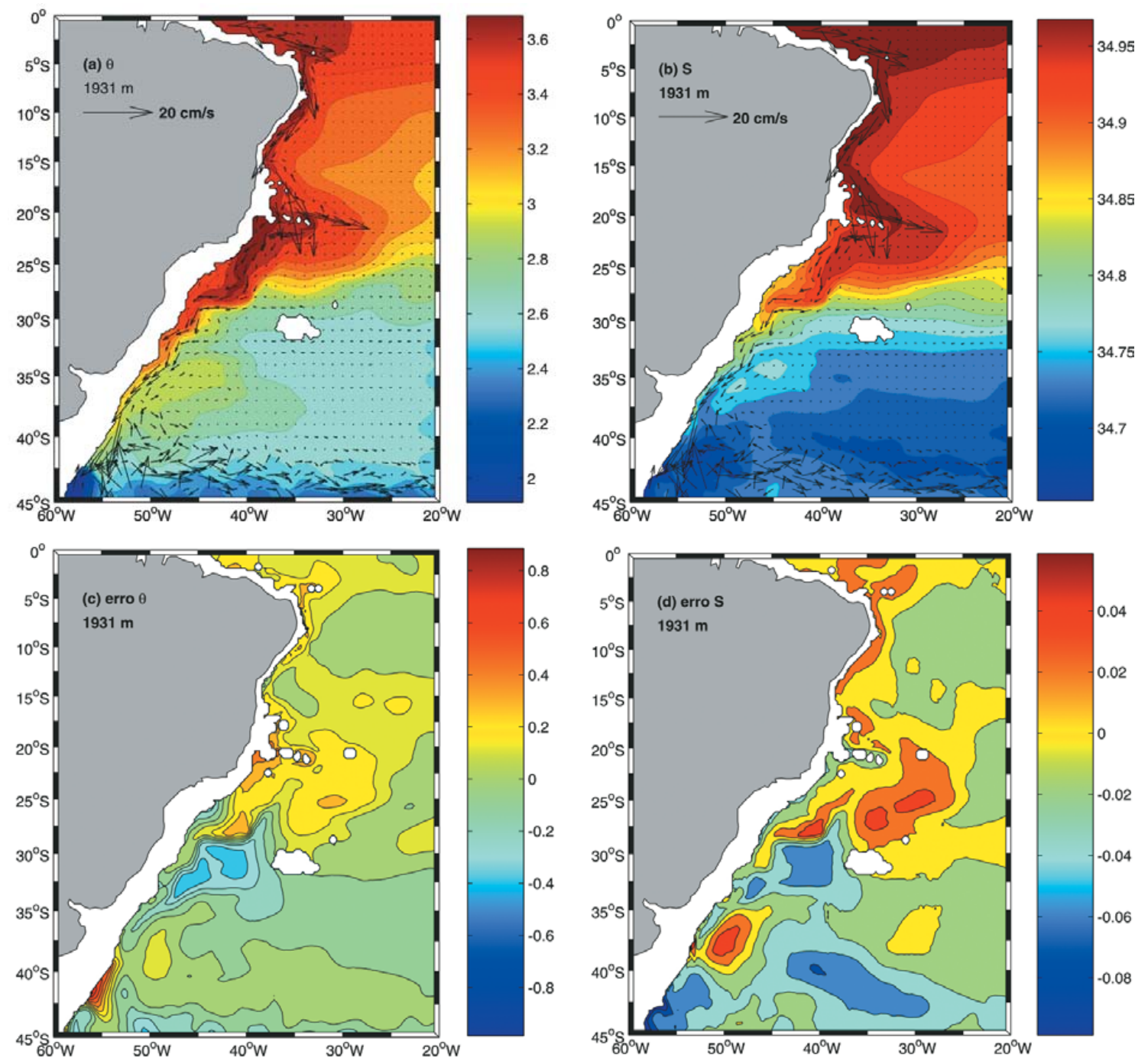

Figura 10 - Análoga a Figura 4, mas para a profundidade de $1931 \mathrm{~m}$. (a) e (c) espaçamento de 0,1 para as isotermas. (b) e (d) espaçamento de 0,02 para as isohalinas.

como parte integrante da porção sul do giro subtropical e com fluxo organizado para leste. Fu (1981) e com base no método inverso, foi um dos primeiros a estimar o transporte da APAN na região, com um fluxo para sul variando entre 19 e 22 Sv nas proximidades de $30^{\circ} \mathrm{S}$. Schott et al. (2002), a $5^{\circ} \mathrm{S}$ estimaram um transporte de aproximadamente $20 \mathrm{~Sv}$ para a APAN, enquanto Dengler et al. (2004), a partir de medidas diretas durante dois anos, estimaram um transporte médio de 19 Sv para a latitude de $11^{\circ} \mathrm{S}$.

Finalmente, e após a análise da distribuição termohalina das massas de água e dos seus respectivos transportes de volume, decidiu-se, através da plotagem de diagramas TS médios, analisar os erros termohalinos (e a compensação de densidade) ao longo da coluna d'água. Para isto foram selecionadas 4 regiões dinamicamente distintas (Figura 12), incluindo as regiões oceânicas: i) da bifurcação da CSE, ii) do litoral do Rio de Janeiro, iii) do litoral do Rio Grande do Sul e iv) da confluência da CB e da Corrente das Malvinas.

A análise dos diagramas a e b da Figura 13 mostra que os maiores erros na estimativa da temperatura e da salinidade estão associados à termoclina. As linhas que ligam estes pontos e que mostram a diferença de densidade entre os valores modela- 


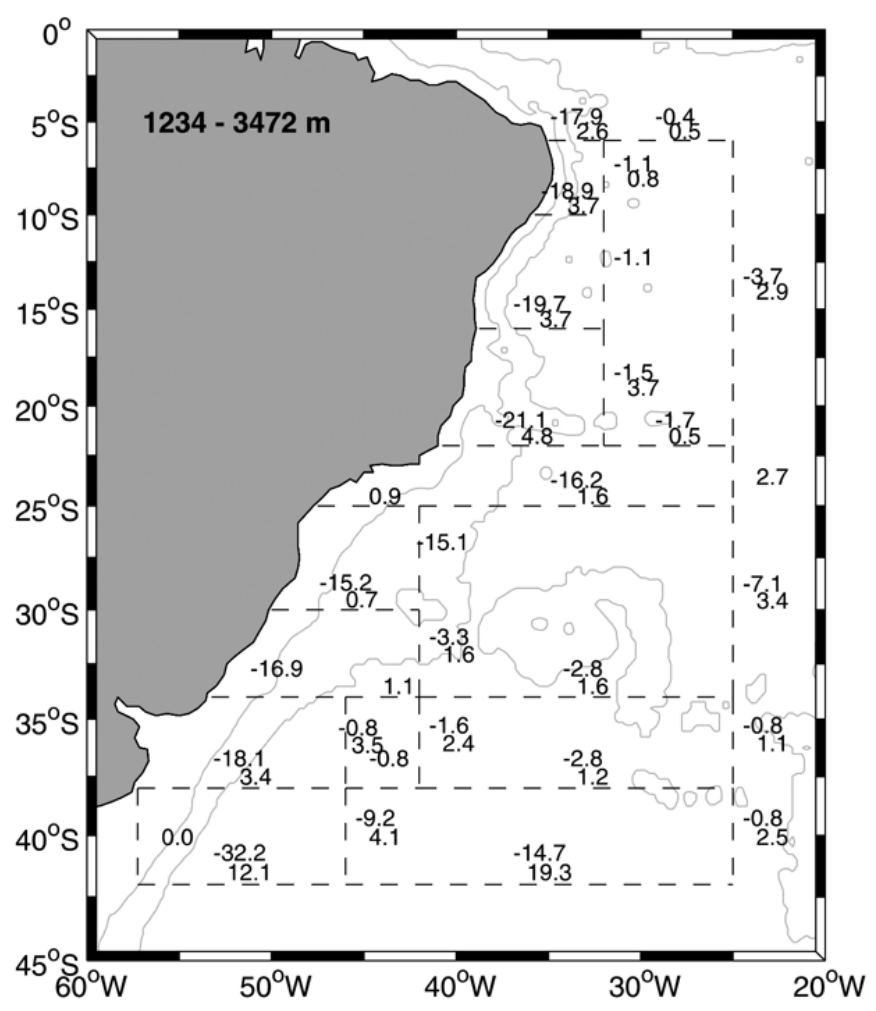

Figura 11 - Análoga a Figura 5, mas para as profundidades entre 1234 m-3472 m, equivalente a APAN.

dos e observados, evidenciam, entretanto, que existe na maioria dos casos, uma considerável compensação do erro. Em termos dinâmicos, isto significa que o modelo fornecerá uma melhor estimativa dos transportes de volume associados, mesmo com fluxos de calor e sal relativamente incorretos. Com relação às diferenças na estrutura de densidade, o diagrama mais crítico é 0 da Figura 13c, que apresenta consideráveis variações de densidade na região da termoclima. Considerando apenas as variações de temperatura e salinidade, as maiores alterações ocorreram próximas à confluência (Figura 13d), o que já era esperado, uma vez que está é uma região extremamente dinâmica. Felizmente, 0 nível de compensação do erro associado com a densidade próximo à confluência, também foi bem elevado.

Um outro ponto importante na análise dos resultados de modelos numéricos está relacionado à espessura da camada de mistura. Para a avaliação do comportamento da camada de mistura no OCCAM foram estimadas as espessuras: i) da camada isotérmica, definida pela faixa de profundidade onde a variação de temperatura em relação à temperatura superficial é menor ou igual a $0,5^{\circ} \mathrm{C}$ e ii) da camada isopicnal, definida de forma análoga, mas para $\sigma_{\theta}$, representando uma variação menor ou igual a 0,125.

As camadas isotérmica e isopicnal são apresentadas nas Figuras 14a e 14b respectivamente, e com exceção da região da confluência Brasil-Malvinas, apresentam valores bastante similares, indicando para toda área de estudo, um espessura média de 39,95 m (camada isotérmica) e 38,45 m (camada isopicnal). Os erros associados às camadas isotérmica (Figura 14c) e isopicnal (Figura 14d), quando comparados a climatologia do NODC indicam um tendência do modelo em subestimar a camada de mistura em baixas latitudes (entre $5^{\circ} \mathrm{S}$ e $20^{\circ} \mathrm{S}$ ) e superestimá-la em médias latitudes (entre $20^{\circ} \mathrm{S}$ e $35^{\circ} \mathrm{S}$ ). Os erros médios associados foram de $-0,89 \pm 17,05 \mathrm{~m}$ para a camada isotérmica e de $1,50 \pm 12,46 \mathrm{~m}$ para a camada isopicnal.

Considerando-se que a camada isopicnal apresentou um comportamento similar à camada isotérmica, decidiu-se então avaliar a variação sazonal segundo o OCCAM, com base apenas no comportamento da camada isopicnal. A Figura 15a mostra que, durante 0 verão, a camada isopicnal além de ser mais rasa, é bastante homogênea, apresentando uma espessura média de 31,44 m. Quando comparado ao NODC, o erro médio para o verão 


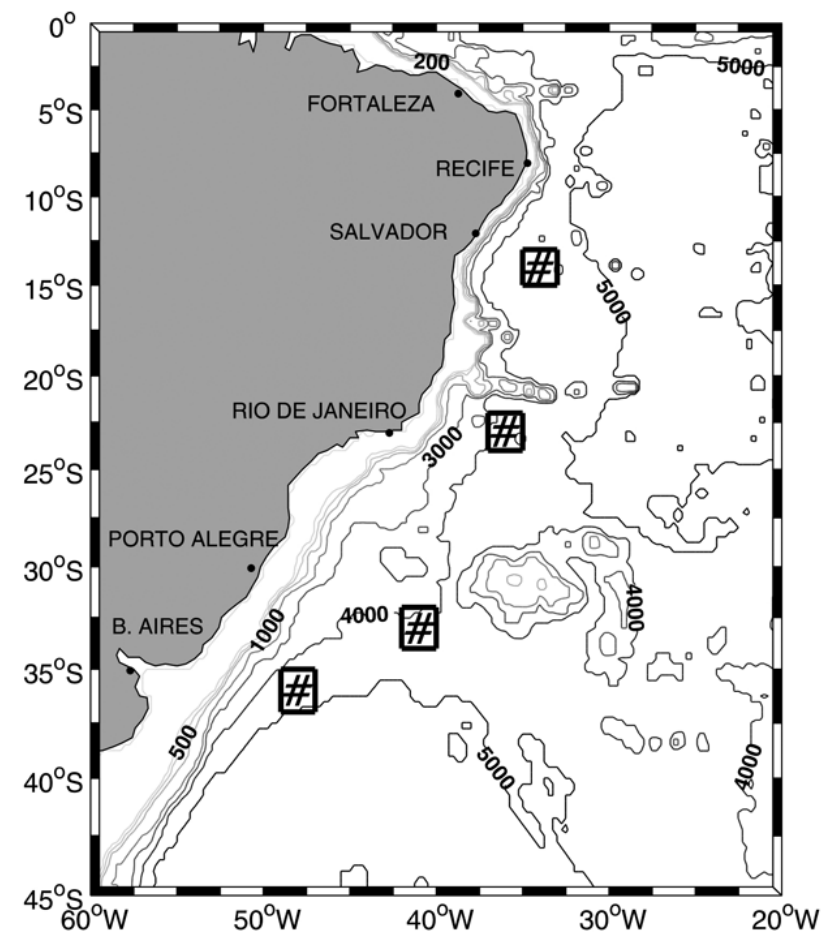

Figura 12 - Mapa batimétrico da região estudo. As caixas representam as regiões escolhidas para gerar os diagramas T-S. As caixas foram posicionadas de forma a englobar até a profundidade máxima do OCCAM.

(Figura 15c) é de 3,18 $\pm 9,20 \mathrm{~m}$. Durante 0 inverno, a menor insolação propicia 0 aprofundamento da camada de mistura (Figura 15b), que é representada no OCCAM com uma profundidade média de 67,49 m e bastante profunda na região associada ao centro do giro subtropical. No entanto, o aprofundamento da camada de mistura, quando comparado ao NODC, é geralmente subestimado em grande parte da área de estudo (Figura 15d), resultando em um erro médio de $-26,58 \pm 46,05 \mathrm{~m}$.

\section{CONCLUSÕES}

Este trabalho apresentou uma análise, com base em uma climatologia anual, do modelo OCCAM para a região oeste do Atlântico Sul. Este estudo incluiu a análise dos campos termohalinos, que foram comparados com a climatologia do NODC e dos valores de transporte, que foram comparados com base nos valores disponíveis na literatura. Stramma \& England (1999) ao revisarem a distribuiç̧ão das massas de água no Atlântico Sul, adotaram quatro níveis principais, sendo AT, ACAS, AIA e APAN. Uma estrutura similar foi adotada para este trabalho, mas neste caso foi utilizada uma definição ligeiramente diferenciada das profundidades associadas com as massas de água.
A análise dos campos termohalinos mostrou que os maiores erros na temperatura e na salinidade estiveram associados à região da Confluência Brasil-Malvinas, que é a região mais dinâmica da área de estudo. De acordo com o nível em questão, os erros podem estar associados tanto com a posição meridional como zonal da confluência. Um fator que pode influenciar no posicionamento da confluência é a má representação, por parte do OCCAM, da Corrente das Malvinas e da retroflexão da CB, uma vez que a resolução espacial de $1 / 4^{\circ} \times 1 / 4^{\circ}$ do modelo pode não permitir uma representação adequada dos fenômenos de mesoescala. Um item que também deve ser levado em consideração é a densidade amostral dos pontos que compõem a própria climatologia do NODC para esta região específica, uma vez que sendo esta uma região tão dinâmica, uma maior amostragem em uma determinada estação do ano poderia ser responsável por parte desta anomalia.

Em termos comparativos e se quantificarmos os erros associados com a temperatura e a salinidade com as alterações causadas na densidade, o modelo apresentou erros mais significativos para a temperatura, com erros médios variando entre um máximo de $0,81 \pm 1,17^{\circ} \mathrm{C}$ para 0 núcleo da ACAS e 

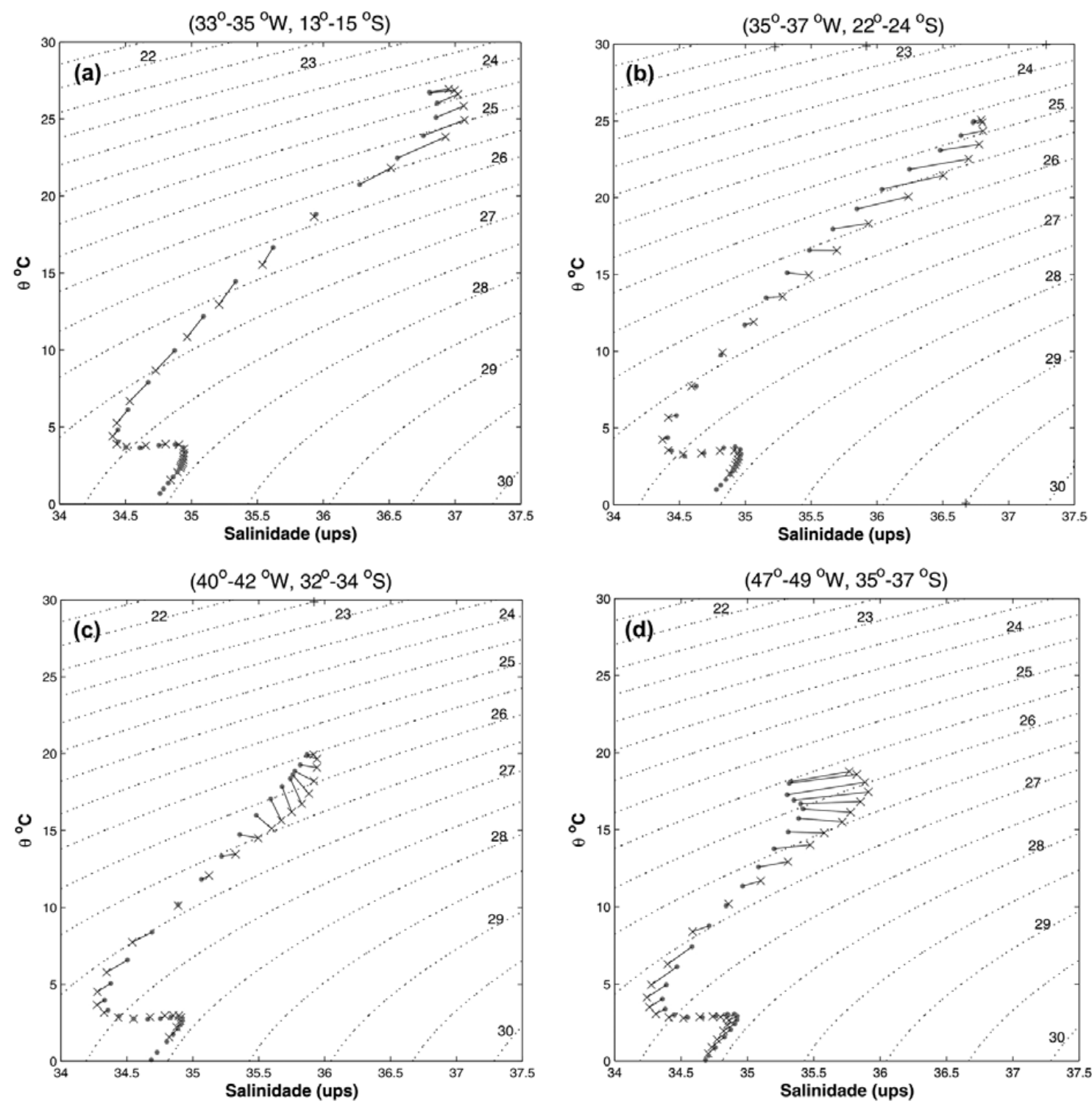

Figura 13 - Diagramas T-S baseados em médias para as caixas de $2^{\circ} \times 2^{\circ}$ apresentadas na Figura 12 e incluindo as regiões oceânicas: (a) da bifurcação da CSE, (b) do litoral do Rio de Janeiro, (c) do litoral do Rio Grande do Sul e (d) da Confluência Brasil-Malvinas. Os pontos (•) representam os valores do OCCAM, enquanto que os pontos $(x)$ representam a climatologia do NODC para o mesmo nível. Para facilitar a análise, foram traçadas as linhas unindo os pontos entre OCCAM $e$ NODC para cada um dos níveis do modelo.

um mínimo de $0,06 \pm 0,13^{\circ} \mathrm{C}$ para o núcleo da APAN. Para a salinidade, estes erros médios variaram entre um máximo de $-0,19 \pm 0,18$ ups para o núcleo da AT e um mínimo de $-0,01 \pm 0,02$ ups para o núcleo da APAN. Observa-se, entretanto, que existe na maioria dos casos, uma certa compensação nos erros associados com a densidade, ou seja, quando a tempe- ratura do modelo é superior (inferior) a observada, a salinidade modelada também aumenta (diminui). Os maiores erros associados com a densidade estiveram vinculados ao nível da ACAS, onde 0 erro médio de $-0,15 \pm 0,12$ foi pelo menos cinco vezes maior do que nos outros níveis. Cirano (2000) analisando a estrutura termohalina do OCCAM para o Oceano Índico obser- 

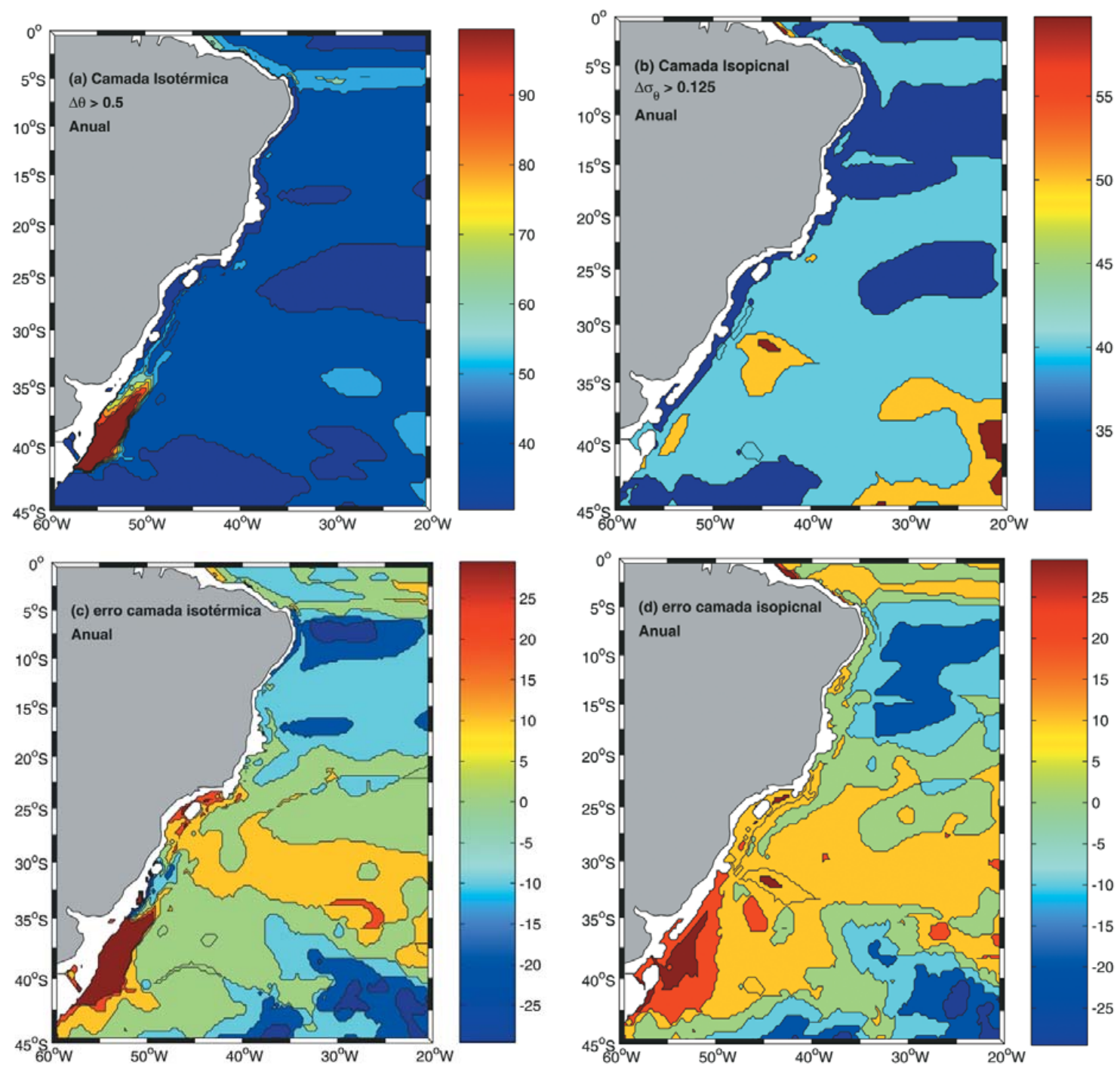

Figura 14 - Espessura da (a) camada isotérmica e (b) camada isopicnal segundo a climatologia anual do OCCAM. (c) Distribuição horizontal do erro para a camada isotérmica, obtido pela diferença entre 0 apresentado em (a) e a camada isotérmica calculada segundo a climatologia anual do NODC. (d) Análogo a (c), mas para a camada isopicnal apresentada em (b). 0 intervalo de contorno entre as isolinhas é de $10 \mathrm{~m}$.

vou que erros na densidade podem estar relacionados a uma má determinação da camada de mistura pelo modelo ou a um excesso de mistura vertical em algumas regiões.

Com relação à circulação e analisando inicialmente a componente barotrópica, os resultados do OCCAM foram coerentes com o modelo de Sverdrup descrito por Godfrey (1989), tanto na determinação da posição zonal do giro como na estimativa do seu transporte máximo (35 Sv).

Para a estrutura vertical, o modelo também representou rea- listicamente 0 achatamento zonal do giro subtropical com 0 aumento da profundidade. Este achatamento vertical ocorreu principalmente na porção norte do giro subtropical, resultando em uma bifurcação da CSE em CB/CNB entre as latitudes de $9^{\circ} \mathrm{S}-15^{\circ} \mathrm{S}$ (nível da AT), em CB/SNB nas proximidades da latitude $25^{\circ} \mathrm{S}$ (nível da ACAS) e da AIA (associada a Corrente de Contorno Oeste Intermediária) entre as latitudes de $25^{\circ} \mathrm{S}-30^{\circ} \mathrm{S}$. Com exceção da ACAS, cuja bifurcação encontrou-se cerca de $3^{\circ}$ mais ao sul, os valores encontrados foram coerentes com o descrito na litera- 

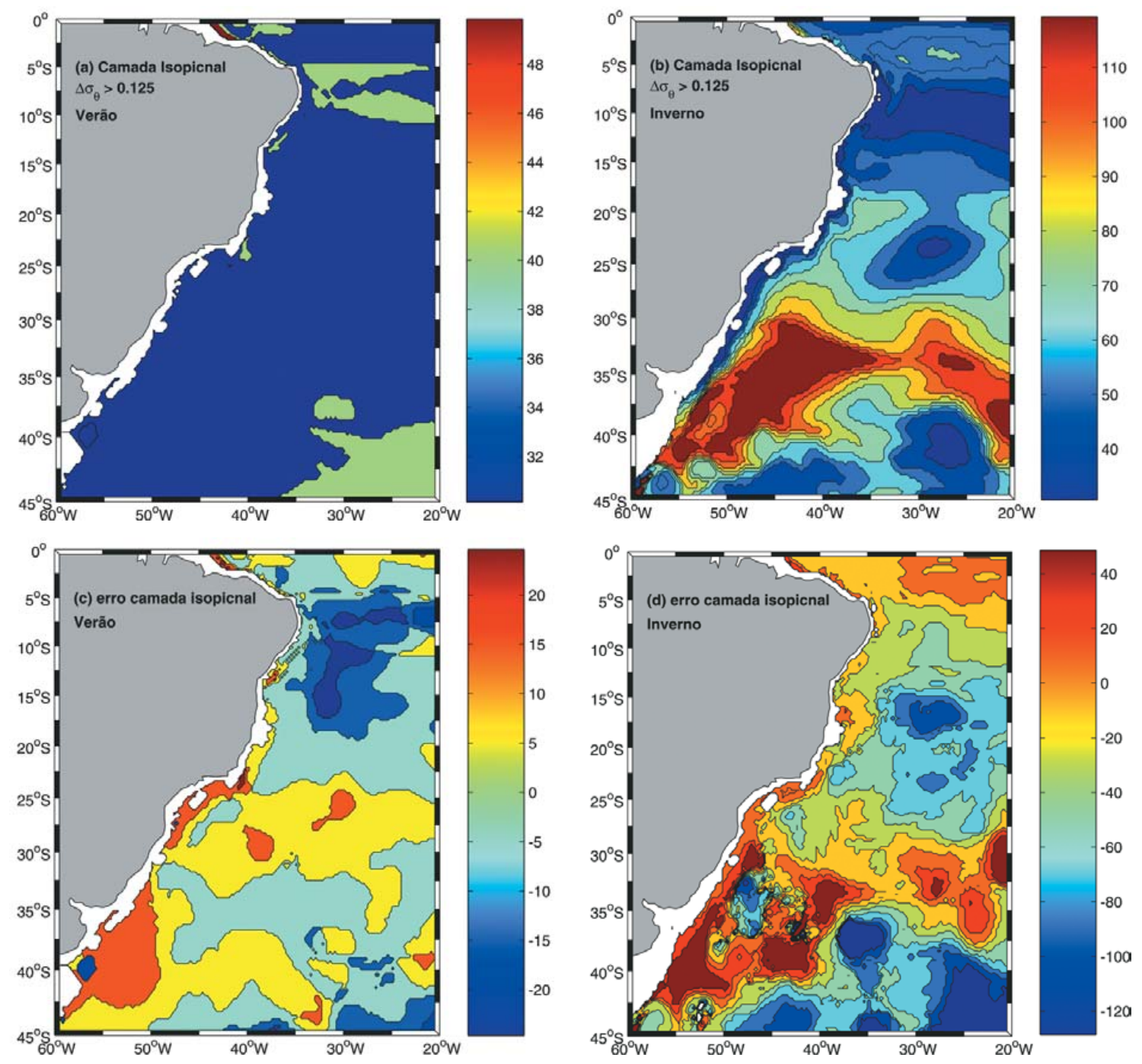

Figura 15 - Espessura da camada isopicnal segundo a climatologia de (a) verão e (b) inverno do OCCAM. (c) Distribuição horizontal do erro para a camada isopicnal durante 0 verão, obtido pela diferença entre 0 apresentado em (a) e camada isopicnal calculada segundo a climatologia de verão do NODC. (d) Análogo a (c), mas para 0 inverno. 0 intervalo de contorno entre as isolinhas é de $10 \mathrm{~m}$ para (a) e (c) e $20 \mathrm{~m}$ para (b) e (d).

tura (e.g. Stramma \& England, 1999; Stramma \& Schott, 1999; Silveira et al., 2000). Uma possível explicação para a variaçãa zonal da bifurcação pode estar associada às alterações do bombeamento de Ekman e da profundidade da camada de mistura ao longo da costa brasileira, que através da dinâmica de Sverdrup definiriam a posição de bifurcação ao longo da coluna d'água. 0 aumento do transporte de Sverdrup com o distanciamento da região equatorial e no sentido do centro do giro subtropical atuaria então para definir a zonação das bifurcações ao longo da coluna d'água.
Em termos do transporte das massas de água e associado as principais correntes, O OCCAM apresentou valores muito próximos dos descritos por Silveira et al. (1994) para SNB, fluindo para norte com um máximo valor líquido de 16,3 Sv. A CB prescrita pelo modelo atingiu um valor máximo de 10,6 Sv (nível da AT somado com o da ACAS) para a latitude de $30^{\circ} \mathrm{S}$. Apesar de apresentar um valor de transporte crescente com 0 aumento da latitude, os valores modelados foram geralmente menores do que os descritos na compilação realizada por Silveira et al. (2000) e apresentada na Tabela 2. 0 modelo, entretanto, foi capaz de re- 
presentar o jato costeiro oposto a CB na costa da Bahia, conforme descrito por Stramma et al. (1990). Abaixo da ACAS, o modelo apresentou valores de transporte bastante coerentes para a AIA, principalmente para o fluxo em direção ao norte, que variou entre 2,9 Sv e 6,2 Sv e esteve de acordo com os valores descritos por Schmid (1998) e Silveira et al. (2004). Schmid (1998) atribui uma relação de 1:2 no transporte do ramo sul da AIA, a qual no modelo apresentou magnitude similar ao ramo norte. Para o nível da APAN, os transportes líquidos para sul variaram entre $15 \mathrm{~Sv}$ e 20 Sv, e também foram concordantes com os observados por Schott et al. (2002) e Dengler et al. (2004).

Finalmente, podemos concluir que o modelo OCCAM, no âmbito de uma climatologia anual, apresentou resultados coerentes com os descritos na literatura. 0 nível da ACAS foi 0 que apresentou os maiores desvios, tanto com relação ao posicionamento da bifurcação da CSE como com relação aos erros na estrutura do campo de massa. Uma provável causa para 0 erro de posicionamento da bifurcação neste nível, pode estar associada a uma superestimativa das ondas equatoriais pelo modelo, o que implicaria no deslocamento para sul da região de bifurcação. A utilização dos dados climatológicos anuais do OCCAM pode, desta forma, ser de grande utilidade na inicialização e na prescrição de condiçõos de contorno para modelos regionais em uma escala espacial e temporal mais detalhada.

Apesar dos bons resultados com relação à climatologia anual do OCCAM, acredita-se que uma análise no âmbito sazonal e para o mesmo modelo, não seria tão eficiente. A análise da variação sazonal da camada de mistura do OCCAM, quando comparada à climatologia do NODC, indica que o período mais crítico é 0 relacionado ao inverno, onde o erro médio é de $-26,58 \pm 46,05 \mathrm{~m}$. Para a climatologia anual do OCCAM, o erro médio associado à espessura da camada de mistura é de apenas 1, 50 $\pm 12,46 \mathrm{~m}$. Para estudos sazonais, sugere-se que sejam analisados os resultados de modelos globais com uma maior resolução, como por exemplo, 0 apresentado por Maltrud \& McClean (2005). No entanto, independente do modelo utilizado, validações no âmbito sazonal e para a região de estudo, ainda ficariam limitadas pela própria escassez de dados observacionais representativos desta variabilidade. Neste âmbito, um dos estudos pioneiros em andamento para a aquisição de uma longa série de dados para 0 monitoramento da variabilidade sazonal e interanual associada à CB está relacionado ao projeto MOVAR - Monitoramento da Variabilidade Regional do transporte de calor na camada superficial do oceano Atlântico Sul entre o Rio de Janeiro (RJ) e a llha de Trindade (ES).

\section{AGRADECIMENTOS}

Os autores agradecem a B.A. de Cuevas do Southampton Oceanography Centre, na Inglaterra, que gentilmente cedeu os dados do OCCAM para estas análises. Este trabalho é parte integrante dos projetos: PETROBAHIA - CTPETRO/CNPq (processo número 500189/2002-1), MARBOBA - CTPETR0/ CNPq (processo número 502356/2003-0), MOVAR - CNPq (processo número 480705/2004-6), PRO-ABROLHOS - INSTITUTO MILÊNIO/CNPq (processo número 420219/2005-6), SACC/CRN1-061 - IAI e da rede 05/01 PETRORISCO CTPETRO/FINEP/CNPq. Os co-autores Edmo José Dias Campos e Núbia Fontes Reis Deiró agradecem ao CNPq pela concessão das suas bolsas de produtividade de pesquisa (processo número 307785/2004-1) e apoio técnico (processo número 360507/2006-9).

\section{REFERÊNCIAS}

BOEBEL 0, DAVIS RE, OLLITRAULT M, PETERSON RG, RICHARDSON PL, SCHMID C \& ZENK W. 1999. The Intermediate Depth Circulation of the Western South Atlantic. Geophys. Res. Lett., 26(21): 3329-3332.

BOYER T, LEVITUS S, GARCIA H, LOCARNINI RA, STEPHENS C \& ANTONOV J. 2005. Objective analyses of annual, seasonal, and monthly temperature and salinity for the world ocean on a 0.25 degree grid. J. Climatol., 25(7): 931-945.

BRYAN K. 1969. A numerical method for the study of the circulation of the world ocean. J. Comput. Phys., 4(3): 347-376.

CAMPOS EJD, GONÇALVES JE \& IKEDA Y. 1995. Water mass structure and geostrophic circulation in the South Brazil Bight - Summer of 1991. J. Geophys. Res., 100(C9): 18537-18550.

COX MD. 1984. A primitive equation 3-dimensional model of the ocean. GFDL Ocean Group Tech. rep. 1, Geophysical Fluid Dynamics Laboratory/NOAA, Princeton University, Princeton, E.U.A, 143 p.

CIRANO M. 2000. Wintertime Circulation within the Southeast Indian Ocean: A Numerical Study. Tese de Doutorado. University of New South Wales, Australia. $213 \mathrm{p}$.

CIRANO M \& MIDDLETON JF. 2004. Aspects of the Mean Wintertime Circulation along Australia's Southern Shelves: Numerical Studies. J. Phys. Oceanogr., 34(3): 668-684.

DEFANT A. 1941. Die absolute Topographie des physikalischen Meeresniveaus un der Druckflächen, sowie die Wasserbewegungen im Raum des Atlantischen Ozean. Wissenschaftliche Ergebnisse Deutschen Atlantischen Expedition auf dem Forschungs und Vermessungsschiff. "Meteor" 1925-1927, 6(2): 191-260. 
DENGLER M, SCHOTT FA, EDEN C, BRANDT P, FISHER J \& ZANTOPP RJ. 2004. Break-up of the Atlantic deep western boundary current into eddies at $8^{\circ} \mathrm{S}$. Nature, 432 (23/30): 1018-1020.

EMILSON I. 1961. The shelf and coastal waters off Southern Brazil. Bolm Inst. Oceanogr., São Paulo, 17(2): 101-112.

EVANS DL, SIGNORINI SR \& MIRANDA LB. 1983. A note on the transport of the Brazil Current. J. Phys. Oceanogr., 13(9): 1732-1738.

EVANS DL \& SIGNORINI SR. 1985. Vertical structure of the Brazil Current. Nature, 315(6014): 48-50.

FISHER A. 1964. The circulation and stratification of the Brazil Current. Dissertação de mestrado. New York University. 86 p.

FU L-L. 1981. The General Circulation and Meridional Heat Transport of the Subtropical South Atlantic Determined by Inverse Methods. J. Phys. Oceanogr., 11: 1171-1193.

GARFIELD III, N. 1990. The Brazil Current at subtropical latitudes. Tese de doutorado. University of Rhode Island. $121 \mathrm{p}$.

GODFREY JS. 1989. A Sverdrup model of the depth-integrated flow for the world ocean allowing for island circulations. Geophys. Astrophys. Fluid Dynamics, 45: 89-112.

HELLERMAN S \& ROSENSTEIN M. 1983. Normal monthly wind stress over the world ocean with error estimates. J. Phys. Oceanogr., 13: 10931104.

LEVITUS S \& BOYER TP. 1994. World Ocean Atlas 1994, Volume 4, Temperature. NOAA Atlas, NESDIS 4. 117 p.

LEVITUS S, BURGETT R \& BOYER TP. 1994. World Ocean Atlas 1994, Volume 3, Salinity. NOAA Atlas, NESDIS 3. 99 p.

MALTRUD ME \& MCCLEAN JL. 2005. An eddy resolving global 1/10 ocean simulation. Ocean Modelling, 8: 31-54.

McCLEAN JL, SEMTNER AJ \& ZLOTNICKI V. 1997. Comparisons of mesoscale variability in the Semtner-Chervin 1/4 degrees model, the Los Alamos Parallel Ocean Program 1/6 degrees model, and T0PEX/POSEIDON data. J. Geophys. Res., 102(C11): 25203-25226.

MELLOR GL \& EZER T. 1991. A Gulf Stream Model and an Altimetry Assimilation Scheme. J. Geophys. Res., 96(C5): 8779-9795.

MÉMERY L, ARHAN M, ALVAREZ-SALGADO XA, MESSIAS M-J, MERCIER H, CASTRO CG \& RIOS AF. 2000. The water masses along the western boundary of the south and equatorial Atlantic, Prog. Oceanogr., 47: 69-98.

MIDDLETON JF \& CIRANO M. 2002. A northern boundary current along Australia's southern shelves: The Flinders Current. J. Geophys. Res., 107(C9), 3129, doi:10.1029/2000JC000701.

MIRANDA LB \& CASTRO BM. 1981. Geostrophic flow conditions of the Brazil Current at $19^{\circ} \mathrm{S}$. Ciencia Interamericana, 22(1-2): 44-48.
MIRANDA LB \& CASTRO BM. 1979. Condições do movimento geostrófico das águas adjacentes a Cabo Frio (RJ). Bolm. Inst. Oceanogr., S. Paulo, 28(2): 79-93.

MIRANDA LB. 1985. Forma de correlação T-S de massa de água das regiões costeira e oceânica entre o Cabo de São Tomé (RJ) e a llha de São Sebastião (SP), Brasil. Bolm Inst. Oceanogr., São Paulo, 33(2): 105-119.

MÜLLER TJ, IKEDA Y, ZANGENBERG N \& NONATO LV. 1998. Direct measurements of the western boundary currents between $20^{\circ} \mathrm{S}$ and $28^{\circ}$ S. J. Geophys. Res. 103(C3): 5429-5437.

NUÑES-RIBONI I, BOEBEL 0, OLLITRAULT M, YOU Y, RICHARDSON PL, DAVIS R. 2005. Lagrangian circulation of Antarctic Intermediate Water in the subtropical South Atlantic. Deep Sea Res. II, 52: 545-564.

OEY LY \& CHEN P. 1992. A Nested-Grid Ocean Model: With Application to the Simulation of Meanders and Eddies in the Norwegian Coastal Current. J. Geophys. Res., 97(C12): 20063-20086.

OLSON DB, PODESTA GP, EVANS RH \& BROWN OB. 1988. Temporal variations in the separation of Brazil and Malvinas Currents. Deep Sea Res., 35(12): 1971-1990.

PETERSON R \& STRAMMA L. 1991. Upper-level circulation in the South Atlantic Ocean. Progr. Oceanogr., 26(1): 1-73.

REID JL, NOWLIN WD \& PATZERT WC. 1977. On the Characteristics and Circulation of the Southwestern Atlantic Ocean. J. Phys. Oceanogr., 7: 62-91.

REID JL. 1989. On the total geostrophic circulation of the South Atlantic Ocean: Flow patterns, tracers and transports. Prog. Oceanogr., 23: 149-244.

SAUNDERS PM, COWARD AC \& CUEVAS BA. 1999. Circulation of the Pacific Ocean seen in a global ocean model: Ocean Circulation and Climate Advanced Modelling project (OCCAM). J. Geophys. Res., 104(C8): 18281-18299.

SCHMID C. 1998. Die Zirkulation des Antarktischen Zwischenwassers im Südatlantik, Ph.D. Thesis, University of Kiel, Kiel, Germany.

SCHOTT FA, BRANDT P, HAMANN M, FISHER J \& STRAMMA L. 2002. On the boundary flow off Brazil at $5-10^{\circ} \mathrm{S}$ and its connection to the interior tropical Atlantic. Geophys. Res. Lett., 29 (17), 1840, doi: 10.1029/2002GL014786.

SEMTNER AJ. 1974. A general circulation model for the World Ocean. Tech. rep. 9, Department of Meteorology, University of California, Los Angeles, $99 \mathrm{p}$.

SIEFRIDT L \& BARNIER B. 1993. Banque de Données AVISO Vent/flux: Climatologie des Analyses de Surface du CEPMMT. Report No 911430 025. $43 p$. 
SIGNORINI SR. 1978. On the circulation and the volume transport of the Brazil Current between the Cape of São Tomé and Guanabara Bay. DeepSea Res., 25: 481-490.

SILVEIRA ICA, MIRANDA LB \& BROWN WS. 1994. On the origins of the North Brazil Current. J. Geophys. Res., 99(C11): 22501-22512.

SILVEIRA ICA, SCHMIDT ACK, CAMPOS EJD, GODOI SS \& IKEDA Y. 2000. A Corrente do Brasil ao largo da Costa Leste Brasileira. Rev. Bras. oceanogr., 48(2): 171-183.

SILVEIRA ICA, CALADO L, CASTRO BM, CIRANO M, LIMA JAM \& MASCARENHAS AS. 2004. On the baroclinic structure of the Brazil Current-Intermediate Western Boundary Current System at $22^{\circ} \mathrm{S}-23^{\circ} \mathrm{S}$. Geophys. Res. Lett., 31, L14308, doi:10.1029/2004GL020036.

STAMMER D, TOKMAKIAN R, SEMTNER A \& WUNSCH C. 1996. How well does a $1 / 4^{\circ} \mathrm{global}$ circulation model simulate large-scale oceanic observations? J. Geophys. Res., 101(C11): 25779-25811.

STRAMMA L. 1989. The Brazil Current transport south of $23^{\circ} \mathrm{S}$. DeepSea Res., 36: 639-646.

STRAMMA L. 1991. Geostrophic transport of the South Equatorial Current in the Atlantic, J. Mar. Res., 49(2): 281-294.

STRAMMA L, IKEDA Y \& PETERSON RG. 1990. Geostrophic transport in the Brazil Current region north of $20^{\circ}$ S. Deep-Sea Res., 37(12): 18751886.
STRAMMA L \& ENGLAND M. 1999. On the water masses and mean circulation of the South Atlantic Ocean. J. Geophys. Res.,104(C9): 20863-20883.

STRAMMA L \& SCHOTT F. 1999. The mean flow field of the tropical Atlantic Ocean. Deep-Sea Res., Part II, 46: 279-303.

SVERDRUP HU, JOHNSON MW \& FLEMING RH. 1942. The Oceans: their physics, chemistry and general biology. Englewood Cliffs, PrenticeHall Inc. 1087 p.

TOMCZAC M \& GODFREY JS. 1994. Regional Oceanography: An Introduction. Pergamon Press, $422 \mathrm{p}$.

TSUCHIYA M. 1986. Thermostats and circulation in the upper layer of the Atlantic Ocean. Prog. Oceanogr., 16(4): 235-267.

WEATHERLY GL. 1993. On deep-current and hydrographic observations from a mudwave region elsewhere in Argentine basin. Deep-Sea Res. Part II, 40(4/5): 939-961.

WEBB D, CUEVAS BA \& COWARD AC. 1998. The first main run of the OCCAM global ocean model. Tech. rep. 34, Southampton Oceanography Centre, $43 \mathrm{p}$.

WÜST G. 1935. Schichtung und Zirkulation des Atlantischen Ozeans. Die Stratosphäre des Atlantischen Ozeans. Wissenschaftliche Ergebnisse Deutschen Atlantischen Expedition auf dem Forschungs und Vermessungsschiff. "Meteor" 1925-1927, 6: 109-228.

\section{NOTAS SOBRE OS AUTORES}

Mauro Cirano é graduado em Oceanografia (FURG/1991) e Mestre em Oceanografia Física (IOUSP/1995). Em 2000 tornou-se Doutor em Oceanografia Física pela University of New South Wales, Sydney, Austrália. Desde 2001, atua com pesquisador do CPGG/UFBA, tendo coordenado e colaborado com vários projetos de pesquisa com ênfase no entendimento da dinâmica oceânica de processos de meso e larga-escala. Desde 2004 é Professor Adjunto do Departamento de Geofísica Nuclear do Instituto de Física da UFBA. Sua linha de pesquisa utiliza tanto a análise de dados observacionais como a modelagem numérica dos processos oceânicos, ferramenta com a qual trabalha a mais de 15 anos.

Mauricio Magalhães Mata é graduado em Oceanografia (FURG/1991) e Mestre em Sensoriamento Remoto (UFRGS/1996). Em 2001 tornou-se Doutor em Oceanografia Física pela Flinders University of South Australia, Adelaide, Austrália. Desde 1992 é Professor permanente do Departamento de Física da FURG. Sua linha de pesquisa concentra-se na circulação oceânica de meso e larga-escala, com ênfase em correntes de contorno oeste e oceanografia Antártica. Tem especial interesse nos processos interanuais que controlam a formação e exportação de águas de fundo no entorno do continente Antártico.

Edmo José Dias Campos é Bacharel e Mestre em Física pela Universidade de Brasília e Doutor em Meteorologia e Oceanografia Física pela Universidade de Miami. Em 1995 obteve o título de Professor Livre-Docente pela Universidade de São Paulo, onde leciona desde 1990, ocupando atualmente o cargo de Professor Associado do IOUSP. Suas linhas de pesquisa principais incluem a circulação Oceânica em meso e Grande Escalas e as Variabilidades Climáticas. Nesse período formou cerca de 20 mestres e doutores e tem sido o coordenador de vários projetos de pesquisa financiados por agências nacionais e internacionais.

Núbia Fontes Reis Deiró é Bacharel em Geofísica pela Universidade Federal da Bahia. Tem atuado na área de geofísica marinha, utilizando métodos eletromagnéticos, e oceanografia física. Participou e acompanhou levantamentos batimétricos em mar aberto e em barragens e levantamentos utilizando perfilador de subfundo (Sub-bottom Profiler) também em mar aberto. Seus interesses de pesquisa envolvem a dinâmica dos oceanos e a geofísica marinha. 